\title{
Induced changes of phenolic compounds in turmeric bread by UV-C radiation
}

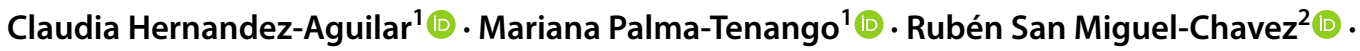 \\ Arturo Dominguez-Pacheco ${ }^{1}$ (1) - Marcos Soto-Hernández ${ }^{2}$ (D) María del Carmen Valderrama Bravo ${ }^{3}$ (D) \\ Rumen Ivanov ${ }^{4}$. Jose Ordoñez-Miranda ${ }^{5}$
}

Received: 8 May 2021 / Accepted: 22 November 2021 / Published online: 26 November 2021

(c) The Author(s), under exclusive licence to Springer Science+Business Media, LLC, part of Springer Nature 2021

\begin{abstract}
Phenolic compounds of breads added with turmeric at different concentrations (A: 0, B: 1.25, C: 2.5, D: 5 and E:10\%) and radiated by UV-C (I. 0, II. 15, III. 30 and IV. 60 s), have been evaluated by HPLC (High-performance liquid chromatography). It is shown that: (i) UV-C radiation modifies the content of phenolic compounds as a function of the percentage of addition of turmeric and the exposure time. There were significant differences $(\rho \leq 0.05)$ in the concentration of phenolic acids of the turmeric bread (TB): $0 \mathrm{~s}$ (sinapic, chlorogenic, protocatechuic), $15 \mathrm{~s}$ (chlorogenic, ferulic, protocatechuic, p-hydroxybenzoic, gallic), $30 \mathrm{~s}$ (chlorogenic and gallic) and $60 \mathrm{~s} \mathrm{(chlorogenic).} \mathrm{(ii)} \mathrm{In} \mathrm{TB} \mathrm{without} \mathrm{radiation} \mathrm{appeared,} \mathrm{the} \mathrm{sinapic,} \mathrm{beta} \mathrm{resor-}$ cylic, syringic and ferulic acids. In the radiation of bread at $15 \mathrm{~s}$, the phenolic acids chlorogenic, ferulic, protocatechuic, p-hydroxybenzoic, gallic, had the highest concentration in the breads added with turmeric at $10 \%\left(0.02 \mu \mathrm{g} \mathrm{mL}^{-1}\right), 10 \%$ $\left(0.38 \mu \mathrm{g} \mathrm{mL}^{-1}\right), 1.25,2.5,5 \%\left(0.39 \mu \mathrm{g} \mathrm{mL}^{-1}\right), 10 \%\left(1.06 \mu \mathrm{g} \mathrm{mL}^{-1}\right)$ and $0 \%\left(1.10 \mu \mathrm{g} \mathrm{mL}^{-1}\right)$. (iii) There was a degradation of phenolic acids due to UV-C radiation at 30 and $60 \mathrm{~s}$. At $15 \mathrm{~s}$ radiation, sinapic, beta resorcylic, syringic and ferulic acids were not detected in turmeric breads from breads added with turmeric at $(1.25,1.25,0$ and $0 \%)$. In radiation at $60 \mathrm{~s}$, beta resorcylic, syringic and ferulic acids were not detected in any bread added with turmeric. In addition, measurements of proximate chemistry, color, sensory analysis, and number of fungal colonies were performed. It is important to mention that the sanitary quality is improved by both UV-C radiation and turmeric. However, the highest results in sanitary quality improvement were due to turmeric.
\end{abstract}

Keywords Bread $\cdot$ Secondary metabolites $\cdot$ UV-C radiation $\cdot$ Turmeric

Arturo Dominguez-Pacheco

fartur@hotmail.com

Claudia Hernandez-Aguilar

clauhaj@yahoo.com

1 Instituto Politécnico Nacional-ESIME Zacatenco - SEPIPrograma en Ingeniería de Sistemas-Sistemas Biofísicos, Col. Lindavista, C.P. 07738 Ciudad de México, México

2 Posgrado en Botánica. Colegio de Postgraduados, Campus Montecillo, Km. 36.5 Carretera Federal México-Texcoco, Texcoco, C.P. 56101 Estado de México, México

3 FES-Cuautitlán, U. N. A. M., Campus 4, km 2.5 Carretera Cuautitlán-Teoloyucan, San Sebastian Xhala, C.P. 54714 Edo de México, México

4 Unidad Académica de Física, Universidad Autónoma de Zacatecas, A.P. 580, Zacatecas, México

5 Institut Pprime, CNRS, Université de Poitiers, ISAE-ENSMA, Futuroscope, 86962 Chasseneuil, France

\section{Introduction}

Food Safety is becoming more and more relevant every day as it has a direct impact on the quality of life of the population. FAO indicates that it is necessary to safe and nutritious food to lead an active and healthy life [1]. Consumption of contaminated food fall to thousands of people $[2,3]$. In this way, various environmentally friendly methods have been used for disinfection processes, among them UV-C radiation is found [4-6], which has been considered as one of the emerging trends in food processing [7].

UV-C method has been applied in agriculture and food [8-11], due to its germicidal effect at wavelengths in the 200-280 nm wavelength range [6, 12]. Evidence of its potential use to reduce or eliminate bacteria, fungi, viruses, and protozoa has been reported by various authors [2, 13-15]. The main applications have been in water, agricultural seed 
and grain, seedlings, plants, post-harvest products and various solid and liquid food products such as milk, cereals, tuna fillets, bread, etc. [16-22].

Bread is one of the main foods in the human diet worldwide [10, 23-26], whose tendency is to make them fortified and without preservatives or chemical additives [25, 27-30]. In this way, when preservatives are not used, a microbial problem occurs due to fungi; the main cause of bread deterioration since it can reduce its useful life generating economic losses and consumer dissatisfaction [24, 31]. The problem increases in high temperature areas [32], being the most common to develop the Mucor, Rhizopus, Aspergillus, Penicillium and Fusarium sp [24, 33-35]. Some of these fungi have been associated with problems of hepatotoxicity, nephrotoxicity, and hyperestrogenism since they are producers of Mycotoxins [36-38]. These are highly toxic metabolites and some fungi that produce them are contained in bread [39], occurring even before fungi are visible [27].

Some authors have reported the contamination of bread after baking, due to the deposit of fungal spores in the environment [27, 40, 41]. Although there are other studies that indicate the existence of the fungus in the raw material used, in the flour and in the wheat used in its preparation [41-43].

Weidenbörner et al. [41] identified in whole wheat and white flour fungi of the genus Aspergillius and to a lesser amount Penicillium and Rizophus. Similary, [44] found the species of fungi of the genus Aspergillius in stored flour, reporting species flavus, niveus, terreus and niger at a rate of $44.5 \%, 37.8 \%, 10.9 \%$ and $6.7 \%$, respectively [45]. Conducted studies of fungi in wheat grain, flour, and bread, coinciding with the types of fungi that were found. In this way, methods that favor its elimination or reduction are required. In this way, UV-C has shown to be useful to extend the shelf life of food products [16]. In this sense, UV-C-light has been applied to the raw material or even to the final product [46-50].

UV-C can be considered an emerging environmentally friendly non-thermal technology for decontamination [51], although it is necessary to generate knowledge related to its effects on nutritional elements such as secondary metabolites (bioactive elements). Different authors have reported that these are modified according to UV-C radiation parameters and characteristics of the biological sample [15, 52]. In this way the aim of this work is to evaluate the phenolic compounds of white wheat bread, added with curcuma (in different concentrations) and irradiated at different UV-C light exposure times. Complementary measurements such as proximate chemistry, color, sensory analysis, and sanitary quality of each type of bread were carried out.

Phenolic compounds are known for their antioxidant, antimutagenic, anticancer, anti-inflammatory, antimicrobial and other properties [53-55], which are of interest for functional food products. UV-C radiation has been reported to modify the content of secondary metabolites and the sanitary quality of foods [56, 57]. Thus, it is of interest to evaluate the effects on white wheat and turmeric bread, as well as to know other characteristics of the bread such as its sanitary quality.

\section{Materials and methods}

\section{Preparation of bread}

Nutritional supplement of turmeric powder-TP (product from India, packaged and distributed in México by company "Mister") with certification Kosher (nutritional information according to label specification: proteins $=8 \mathrm{~g}$, fats $=10 \mathrm{~g}$ (saturated and trans-fat $=0$ ), carbohydrates $65 \mathrm{~g}$, sugars $=0 \mathrm{~g}$ and dietary fiber $=21 \mathrm{~g}$, sodium $=0 \mathrm{~g}$ and energy content $=335 \mathrm{kcal}$ for each $100 \mathrm{~g}$ ) was acquired in the city of Mexico. Bread dough was elaborated at different concentrations of TP (A, B, C, D and E) in proportion to weight of the wheat flour $(600 \mathrm{~g})$. Bread formulations according to Hernández et al. [35] were elaborated with basic ingredients of dry yeast powder (11 g, "Tradi-Pan"), egg (48-50 g, "San Juan"), olive oil (70 g, "Oli de nutrioli"), salt (1.25 g, "Pragna"), sugar (4 g, "Zulca") and warm water (300 mL), appropriate quantity to handle the dough. The formulations expressed by percentage are possible observe in Table 1.

The ingredients were incorporated into the container of the bread mixer (OSTER-Perform inox $600 \mathrm{~W}$ ), starting with the solid ingredients and then the liquid ingredients, adding the sporulated yeast in $150 \mathrm{ml}$ of warm water. The mixer is turned on by placing the spiral hook and it begins to beat. Add the rest of the warm water and continue beating to complete the $5 \mathrm{~min}$. The resulting ball of dough is kneaded with your hands for another $10 \mathrm{~min}$. Then, it is placed in a first rest (30 $\mathrm{min}$ ) in a previously greased container and covered with a cotton cloth. Subsequently, it is kneaded again for another five minutes and placed in a box bread mold (previously greased and sprinkled with wheat flour). Arranging in such a way that the entire bread is covered and letting it rest for $25 \mathrm{~min}$ (second rest). The same procedure was applied for all the breads made. Finally, they were baked in an electric oven (OSTER- 42 L) at a temperature of $180{ }^{\circ} \mathrm{C}$, for $50 \mathrm{~min}$. Once baked, they were placed on bread racks and allowed to cool under room temperature conditions for $24 \mathrm{~h}$. Subsequently, the pieces of bread were cut into slices (1.5 $\mathrm{cm}$ thick) using an electric knife (Hamilton beach type EK08, $121 \mathrm{~V}, 11 \mathrm{~Hz}$ ). The final bread slices present white color and yellow in different shades as shown in Table 1. 
Table 1 Turmeric bread formulations (Color Table online)

\begin{tabular}{|c|c|c|c|c|c|c|c|c|}
\hline Treatments different $\%$ of TP & Bread digital image & Wheat flour (\%) & Olive oil (\%) & $\operatorname{Egg}(\%)$ & Salt (\%) & Sugar $(\%)$ & Yeast (\%) & $\begin{array}{l}\text { Turmeric } \\
\text { powder } \\
(\%)\end{array}$ \\
\hline (A). CB $(0 \mathrm{~g})$ & & 81.72 & 9.53 & 6.54 & 0.17 & 0.54 & 1.5 & 0 \\
\hline (B). TB-1.25\% (7.5 g) & & 80.7 & 9.53 & 6.54 & 0.17 & 0.54 & 1.5 & 1.02 \\
\hline (C). TB-2.5\% (15 g) & & 79.68 & 9.53 & 6.54 & 0.17 & 0.54 & 1.5 & 2.04 \\
\hline (D). TB-5.0\% (30 g) & & 77.63 & 9.53 & 6.54 & 0.17 & 0.54 & 1.5 & 4.09 \\
\hline (E). TB-10 (60 g) & & 73.55 & 9.53 & 6.54 & 0.17 & 0.54 & 1.5 & 8.17 \\
\hline
\end{tabular}

$T P$ Turmeric powder, $T B$ Turmeric bread

Turmeric powder was incorporated in A: 600, B: 592.5, C: 585, D: 570 and E: $540 \mathrm{~g}$ of wheat flour weight

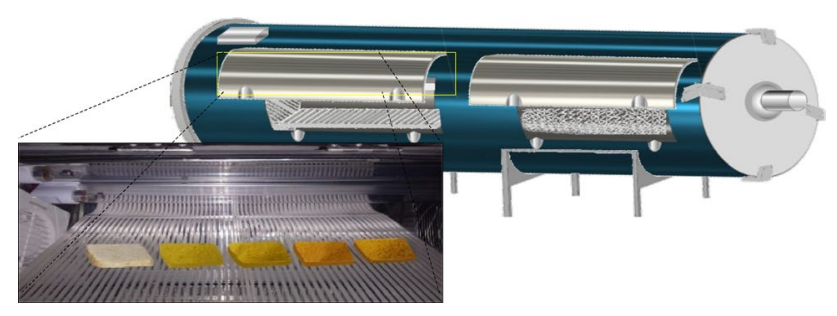

Fig. 1 UV-C radiator system of the bread

\section{Treatment of UV-C radiation}

Breads were treated by UV-C radiator system (UV-C/ SRE (SRE: Seed Radiator Equipment)-HomemadeEsime, Zacatenco) - (Fig. 1). A system of 4 lamps (UV$\mathrm{C}, 254 \mathrm{~nm}$ ) accommodated on the top and bottom of a cylindrical stainless-steel base. The lamps when turned on emit light towards a bases with grids, on which the slices of bread were placed. The slices of bread received radiation from the upper and lower sides of the slices. Several radiation times were applied to the bread: $0,15,30$, and $60 \mathrm{~s}$, programmed through a timer. The light intensity $\left(700 \mu \mathrm{W} / \mathrm{cm}^{2}\right)$ was measured by the UV-C/254 measuring equipment.

\section{Analysis of phenolic acids by HPLC}

Extracts were obtained with $50 \mathrm{mg}$ of dry and pulverized material in $1 \mathrm{~mL}$ of methanol of HPLC grade (SigmaAldrich number 36860 ) at $80 \%$, incubated for $20 \mathrm{~min}$ in an ultrasound bath (BRANSON at Smithkline company $50 / 60 \mathrm{~Hz}$, model B-220, USA [58]. The crude extracts were centrifuged at $731 \mathrm{~g}$ (Eppendorf, Centrifuge model 5804) for $10 \mathrm{~min}$ [59]. Supernatants were filtered with $25 \mathrm{~mm}$ diameter acrodiscs with nylon membrane and $0.45 \mathrm{~mm}$ pore size (Titan). These extracts were injected immediately for the analysis by HPLC of phenolic acids. The samples were analyzed in a Hewlett Packard ${ }^{\circledR}$ chromatograph mod. 1100 provided with diode array detector and an Agilent Technologies automatic injector mod. 1200. The column was a Hypersil ODS HP column of $125 \mathrm{~mm}$ length and $4 \mathrm{~mm}$ internal diameter, $5 \mu \mathrm{m}$ particle size was used. The mobile phase was distilled water, adjusted to $\mathrm{pH}$ 2.5 with trifluoroacetic acid (A) and acetonitrile (B) [60]. The analysis was by gradient: T1 $0.10 \mathrm{~min}(85 \% \mathrm{~A})(15 \%$ B); T2 $20 \min (65 \%$ A) $(35 \% \mathrm{~B})$ and $\mathrm{T} 325 \min (65 \% \mathrm{~A})$, (35\% B), $\lambda=254,280,330$ and $365 \mathrm{~nm}$, Column temperature $30{ }^{\circ} \mathrm{C}$ and flow of $1 \mathrm{~mL} \mathrm{~min}^{-1}$. Calibration curves were performed for standards of phenolic acids: sinapinic, $\beta$-resorcylic, syringic, chlorogenic, ferulic, protocatechuic, p-hydroxybenzoic and gallic (Sigma-Aldrich $\left.{ }^{\circledR}\right)$. The interpolations of all the extracts were calculated with ChemStation software @ Agilent Technologies, Inc. 2004. 


\section{Color and proximate chemical analysis}

The color of the different types of bread was determined in a portable digital colorimeter (FRU). The color parameters corresponding to the CIELAB uniform color space $\left(\mathrm{a}^{*}\right.$, $\mathrm{b}^{*}$ and $\left.\mathrm{L}^{*}\right)$ were obtained directly from the equipment. L* indicates lightness $(100=$ White and $0=$ Black $)$, "a" indicates greenish—reddish [negative (green) to red (positive)] and " $b$ " indicates bluish-yellowish [negative (blue) to yellow (positive)]. The equipment was calibrated using a reference blank $L^{*}=96.65, a=-0.03$ and $b=1.86$.

Chemical analysis was performed according to AACC procedures (2000) [61]. The variables obtained in three replicates were Moisture content (44-15), ash (08-01), protein $(\mathrm{N} \times 5.85)(46-13)$ and fat $(30-25)$.

\section{Sensory analysis}

The sensory analysis was carried according to Laureati et al. (2012) [62] by using of nine points hedonic scale (where $1=$ Dislike Extremely, $2=$ Dislike Very Much, 3 = Dislike Moderately, $4=$ Dislike Slightly, $5=$ Neither Like nor Dislike, 6=Like Slightly, $7=$ Like Moderately, $8=$ Like Very Much and $9=$ Like Extremely). Seven consumers (7) of bread, between 30 and 52 years old ( 5 woman and 2 men), reside in state of Mexico participated in this study. The evaluation was carried out using the procedure described by Hernández-Aguilar et al. (2019) [63] and the application of the respective questionnaire, selecting 10 attributes to be rated: color, porosity, sponginess, hardness, cohesiveness, aroma, chewiness, flavor and preferences and healthy attributes in general.

\section{Fungal effects}

The fungal effect of curcuma and UV-C radiation was through the sanitary quality test $[64,65]$. Experimental design employed was randomized complete blocks with three replicates for each type of bread prepared with different formulations and treated in this research. Slices of bread of each type were selected and placed in bags of polystyrene bags previously sterilized with alcohol. The samples were incubated in a closed room with an average temperature of $25^{\circ} \mathrm{C}$. The observation and quantification of the existing fungal colonies was performed after 7 days of incubation. Observations were made according to Hernandez et al. (2021) [66]. The genus of the fungus was identified according to the taxonomic keys (Ravimannan et al. 2016) [67]. Finally, fungal colony counting, and data recording were performed.

\section{Economic study}

Costs were determined by taking an inventory of the inputs used to make the bread (wheat flour, olive oil, egg, salt, sugar, yeast, turmeric power, water) and obtaining the current costs for their acquisition in Mexico City. Subsequently, the cost was obtained proportionally according to the proportion of the input used. In addition, expenses for labor services and fixed costs of investment in equipment used (blender with a spiral hook, electric oven, and electric knife) were considered. The labor force considered was the average paid in the study locality to a bakery worker profile. The electric energy used for the preparation of bread was considered the use of the work equipment and the time of duration of its use: mixer (15 min), oven electric for preheating (10 min), electric oven for baking bread (50 min) and the electric knife for cutting bread (15 min). The cost of electric energy considered was taking as reference the price per kilowatt-hour according to the intermediate consumption in a domestic environment as established by the Federal Electricity Commission.

\section{Statistical analysis and principal component analysis}

\section{Variance analysis}

The acid phenolic amounts of each treatment (Table 2) were compared by an analysis of variance $(\mathrm{P} \leq 0.05)$ (ANOVA) followed by Tukey test (Fig. 2) [68]. The compilation of the data and all test calculations were performed using SAS software (SAS Institute, 2008) [69].

\section{Principal component analysis (PCA)}

PCA was applied to the experimental data obtained for the variables evaluated in wheat breads made with different concentrations of curcuma (A, B, C, D and E) and irradiated with UV-C $(0,15,30$ and $60 \mathrm{~s})$. The analysis was performed using the R Project software version 0.10-47, with $\mathrm{R}$ Commander and factoMiner and Fitopac program (2.1). The data matrix used was formed from the measurements of the phenolic compounds identified (sinapic, beta resorcylic, syringic, chlorogenic, chlorogenic, ferulic, protocatechuic, p-hydroxybenzoic and gallic).

\section{Results and discussion}

\section{Phenolic acids}

Table 2 presents the analysis of variance of different phenolic acids (sinapic, beta resorcylic, syringic, chlorogenic, 


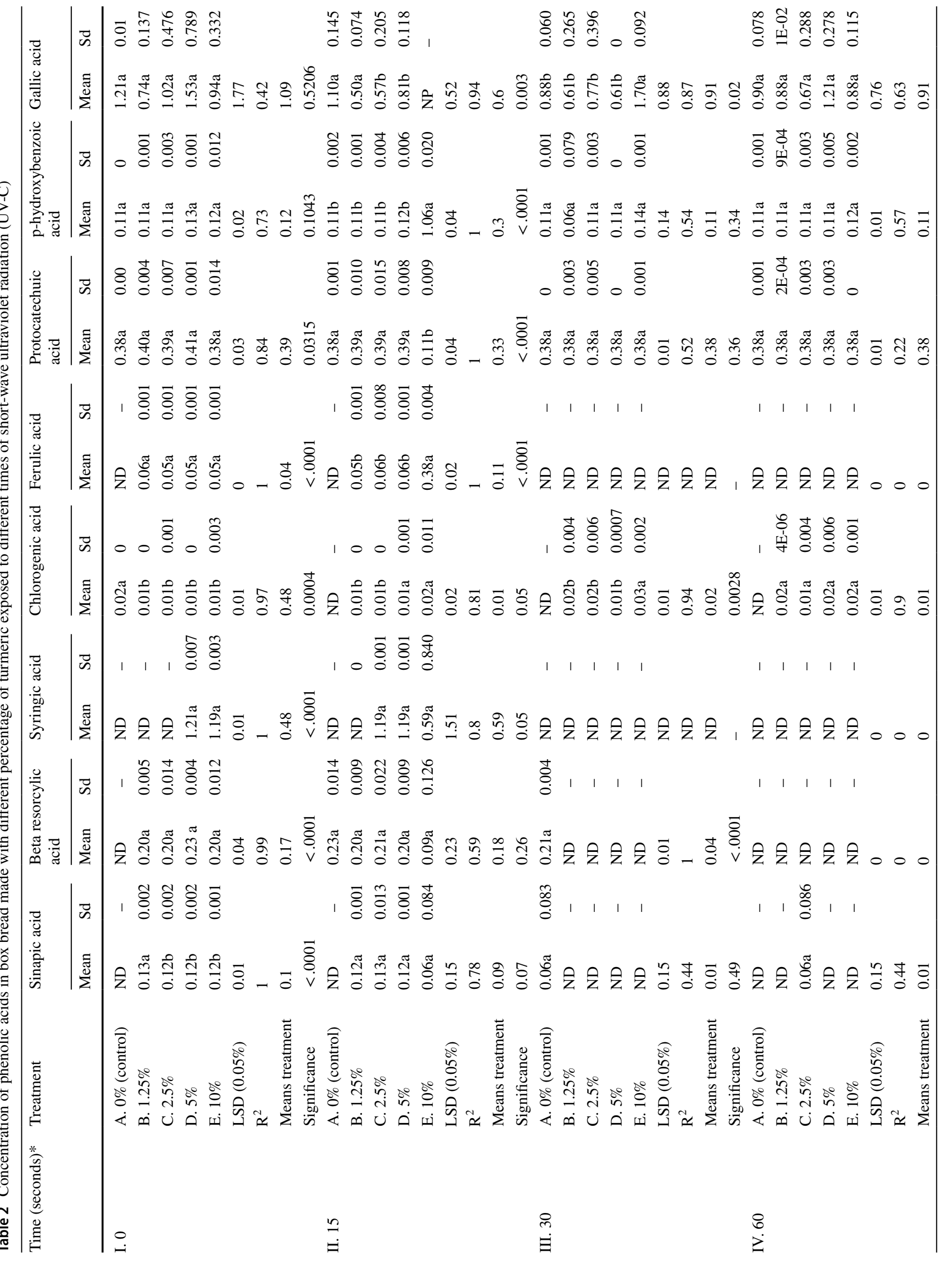


ferulic, protocatechuic, p-hydroxybenzoic and gallic) identified in the box bread made with different percentages of turmeric exposed to different UV-C radiation times. It is possible to observe, for each type of radiation, the set of values corresponding to each type of bread added with turmeric (A, B, C, D and E) and each type of phenolic acid identified. The first set of results corresponds to the bread without UV-C radiation (I. $0 \mathrm{~s}$ ). It can be observed that there were significant differences $(\mathrm{P} \leq 0.05)$ in the concentration of phenolic acids (sinapic, chlorogenic and protocatechuic) of the bread. Among these, the most abundant was protocatechuic $\left(0.41 \pm 0.001 \mu \mathrm{g} \mathrm{mL}^{-1}\right)$, followed by Sinapic acid $\left(0.132 \pm 0.002 \mu \mathrm{g} \mathrm{mL}^{-1}\right)$ in turmeric bread at 5 and $1.25 \%$ TP (D, E). For the type of phenolic compound sinapic, it was found that increases from 0 to $0.132 \pm 0.002 \mu \mathrm{g} \mathrm{mL}^{-1}$ between bread without turmeric (A) and bread with turmeric at $1.25 \%$ (B) and for protocatechuic acid it increased to approximately $9 \%$ when comparing bread without turmeric (A), with the added bread that most increased its content (D). However, chlorogenic acid decreased its content in turmeric added breads (B, C, D, E) by up to $50 \%$ with respect to turmeric-free bread.

Beta resorcylic (1.25, 2.5, 5, and 10\%), syringic (5 and $10 \%)$ and ferulic acids $(1.25,2.5,5$, and $10 \%)$, were identified in turmeric breads at respective percentages of addition of turmeric, i.e. wheat bread (without turmeric) does not possess these phenolic compounds. The level of this phenolic acids tends to present a similar content level between the different breads with the different concentrations of turmeric since no significant statistical differences $(\mathrm{P} \leq 0.05)$ were found between them. Although these acids tended to decrease in turmeric bread $\mathrm{E}$ ( $10 \%$ of TP), with respect to the other breads added with turmeric. Among these compounds, syringic acid was the most abundant $\left(1.20 \pm 0.007 \mu \mathrm{g} \mathrm{mL}^{-1}\right)$, bread D.

The p-hydroxybenzoic and Gallic acids did not present significant differences between the turmeric breads $(0,1.25$, 2.5, 5 and 10\%). These were present in the bread without turmeric and those added with turmeric. Although the p-hydroxybenzoic acid tended to increase in the bread with the increase in the percentage of addition of turmeric and the gallic acid was identified in the lowest levels of content in the breads $\mathrm{C}(2.5 \%)$ and $\mathrm{E}(10 \%)$.

In the set of data presented in Table 2, corresponding to the case of bread radiated with UV-C during $15 \mathrm{~s}$ (I), significant differences $(\mathrm{p} \leq 0.05)$ were found in phenolic acids of the chlorogenic, ferulic, protocatechuic, p-hydroxybenzoic and gallic types. Among these, the most abundant acids were protocatechuic $\left(0.39 \pm 0.015 \mu \mathrm{g} \mathrm{mL}^{-1}\right)$ acid in the samples of bread to B, C, and D $(1.25,2.5,5 \%)$ and gallic $\left(1.10 \pm 0.145\right.$ and $\left.0.81 \pm 0.118 \mu \mathrm{g} \mathrm{mL}^{-1}\right)$ in the samples of breads, A (0\%) and D (5\%). It is important to note that this last acid (gallic) was not identified in 

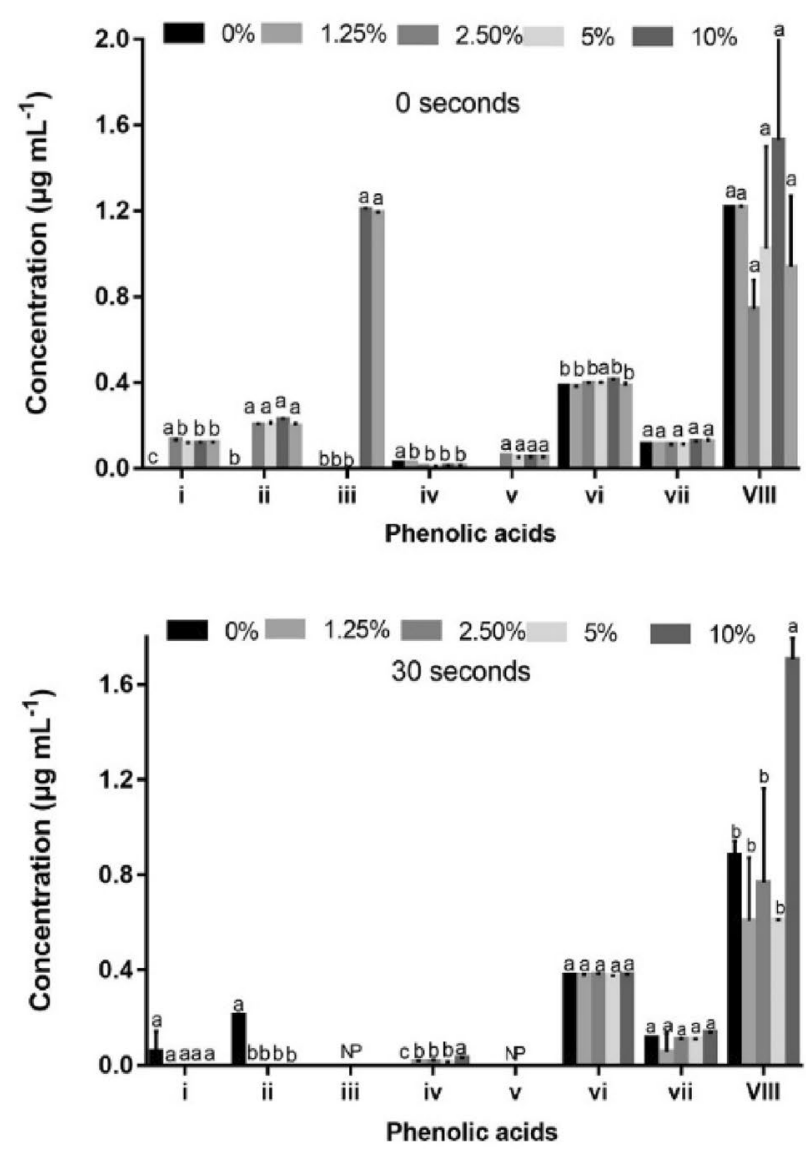

Fig. 2 Concentration of phenolic acids in different percentages of Curcuma Longa L. added to box bread and exposed to different times of UV-C light $(0,15,30$ and 60 s). I. Sinapic acid, II. Beta resorcylic

the bread samples E (10\%). However, p-hydroxybenzoic $\left(1.06 \pm 0.02 \mu \mathrm{g} \mathrm{mL}^{-1}\right)$, chlorogenic $\left(0.02 \pm 0.011 \mu \mathrm{g} \mathrm{mL}^{-1}\right)$ and ferulic $\left(0.38 \pm 0.004 \mu \mathrm{g} \mathrm{mL}^{-1}\right)$ acids had the highest content in these breads (10\%). It should be noted that chlorogenic and ferulic acids were not identified in the bread samples without turmeric (A) at this radiation level (15 s). Although in the case of chlorogenic acid in bread A $(0 \%$ of TP) without radiation (I. $0 \mathrm{~s}$ ), these acids were present $\left(0.02 \pm 0.000 \mu \mathrm{g} \mathrm{mL}^{-1}\right)$.

On the other hand, beta resorcyclic acid was present in the samples of bread added with turmeric and radiated at $15 \mathrm{~s}$, with a similar statistical behavior, although the breads $\mathrm{A}(0 \%)$ and $\mathrm{E}(10 \%)$ had the highest $\left(0.23 \pm 0.014 \mu \mathrm{g} \mathrm{mL}^{-1}\right)$ and the lowest $\left(0.09 \pm 0.126 \mu \mathrm{g} \mathrm{mL}^{-1}\right)$, content of this type of phenolic acid.

Regard to the sinapic and syringic acids, these were not identified in wheat bread without turmeric and radiated during $15 \mathrm{~s}$. They were identified in the breads B $(1.25 \%)$ and $\mathrm{C}(2.5 \%)$, respectively. It should be noted that syringic acid was present in the bread radiated at $15 \mathrm{~s}$, at a lower level of addition of turmeric to the bread (2.5\%), with respect to the
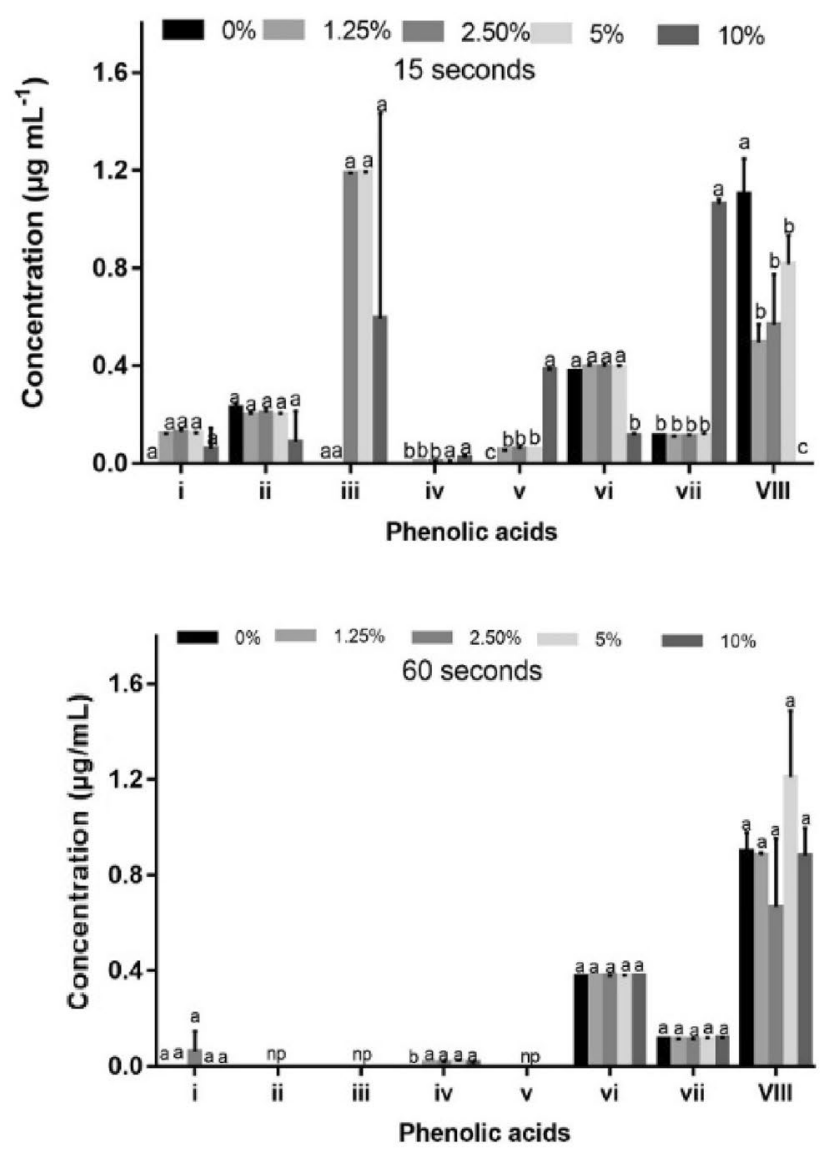

acid, III. Syringic acid IV. Chlorogenic acid V. Ferulic acid VI. Protocatechuic acid VII. 3,5 Dihydroxybenzoic acid VIII. Gallic acid

bread without radiation (I. $0 \mathrm{~s}$ ) that was identified from the bread added with turmeric at 5\% (D).

Breads evaluated at radiation time (15 s) there were no statistically significant differences in the acids (sinapic and syringic). Their contents tended to decrease as the addition of turmeric increases, obtaining the lowest contents of these acids for the breads added to $10 \%(0.06 \pm 0.084$ and $0.59 \pm 0.084 \mu \mathrm{g} \mathrm{mL}^{-1}$, respectively). Among these compounds, syringic acid was the most abundant $\left(0.59 \pm 0.084-1.19 \pm 0.001 \mu \mathrm{g} \mathrm{mL}^{-1}\right)$.

Phenolic compounds identified in bread is decreased by increasing UV-C radiation by 30 (6: sinapic, beta resorcylic, chlorogenic, protocatechuic, p-hydroxybenzoic and gallic) and $60 \mathrm{~s} \mathrm{(5:} \mathrm{sinapic,} \mathrm{chlorogenic,} \mathrm{protocatechuic,} \mathrm{p}$ -hydroxybenzoic and gallic). Due to UV-C radiation was found an apparent degradation of phenolic acids.

Note in Table 2, that for $30 \mathrm{~s}$ (case III), in gallic and chlorogenic phenolic acids, significant differences were found when comparing the different breads (A, B, C, D and E). Gallic acid was the most abundant at this level of radiation $(30 \mathrm{~s})$ of added turmeric breads $(0,1.25,2.5$, 
5 , and $10 \%$ ). The breads at $10 \%$ of TP had the highest contents of gallic acid $\left(1.7 \pm 0.092 \mu \mathrm{g} \mathrm{mL}^{-1}\right)$ and chlorogenic $\left(0.03 \pm 0.002 \mu \mathrm{g} \mathrm{mL}^{-1}\right)$. The protocatechuic and p-hydroxybenzoic acids did not present significant differences $(\mathrm{p} \leq 0.05)$, however, the highest values of these acids were found also in the bread $\mathrm{E}$ samples $(0.38 \pm 0.001$ and $0.14 \pm 0.001 \mu \mathrm{g} \mathrm{mL}^{-1}$, respectively).

In relation to sinapic and beta resorcylic acids, they were present only in the breads to which no turmeric was added (A: 0\%). Apparently, the degradation of these acids is intensified with the addition of turmeric (1.25, $2.5,5$, and $10 \%)$. On the contrary, chlorogenic acid was only present in the bread added with turmeric. Its concentration increases as the addition of turmeric in the bread increased, with the highest concentration in the bread having $10 \%$ addition of turmeric.

Finally, at the radiation time of $60 \mathrm{~s}$ (IV) of the turmeric added breads $(0,1.25,2.5,5$ and $10 \%)$, there were no statistically significant differences in the different types of acids identified (sinapic, chlorogenic, protocatechuic, $\mathrm{p}$-hydroxybenzoic and gallic). Being gallic and protocatechuic acids; the most abundant, presenting the highest values both, in bread $\mathrm{D}(5 \%)$, with values of $1.2 \pm 0.278$ and $0.38 \pm 0.003 \mu \mathrm{g} \mathrm{mL}$ (A, B, C, D, and E). Followed by p-hydroxybenzoic acid with values that ranged between $0.11 \pm 0.001$ and $0.12 \pm 0.002 \mu \mathrm{g} \mathrm{mL}{ }^{-1}$. Regarding chlorogenic acid, it was identified from the $1.25 \%$ turmeric breads (i.e., breads without turmeric was not identified), with the highest level of acid content being the $\mathrm{D}$ bread (5\%). In relation to synapic acid, it was not found in turmeric breads (A, $\mathrm{B}, \mathrm{D}$ and $\mathrm{E})$. It was only found in samples of bread C (2.5\%) with a value of $0.06 \pm 0.008 \mu \mathrm{g} \mathrm{mL}^{-1}$. It should be noted that syringic and ferulic acid occurred only in the radiation of 0 and $15 \mathrm{~s}$, i.e., the breads radiated at $60 \mathrm{~s}$, they were not found.

Figure 2 shown that UV-C radiation modified the concentration of phenolic acids identified in the added bread according to the radiation time $(0 \mathrm{~s}, 15 \mathrm{~s}, 30 \mathrm{~s}$ and $60 \mathrm{~s})$ and to the addition of turmeric in the bread $(0,1.25,2.5,5$ and $10 \%)$. It is observed that with higher UV-C radiation, the concentration level of phenolic acids decreases, being at $0 \mathrm{~s}$ and $15 \mathrm{~s}$, eight types of phenolic acids identified and at 30 and $60 \mathrm{~s}$, six and five were found. It is observed that phenolic acids protocatechuic, p-hydroxybenzoic and gallic, were less affected by UVC- radiation since they were maintained at all levels of applied radiation. Among these, the least affected were protocatechuic and p-hydroxybenzoic. The gallic acid concentration showed a tendency to decrease due to the increase in UV-C radiation for each type of turmeric bread $(0,1.25,2.5,5$ and $10 \%)$. White bread (at zero $0 \mathrm{~s}$ radiation), the gallic acid content interval was between the values of $0.74 \pm 0.137-1.53 \pm 0.789 \mu \mathrm{g} \mathrm{mL}^{-1}$ and at $60 \mathrm{~s}$ radiation the content variation interval in the breads added with turmeric was between $0.6-1.2 \mu \mathrm{g} / \mathrm{mL}$, having a decrease for these limit ranges of 11 and $21 \%$, approximately by UV-C light.

Other authors have reported the stability of secondary metabolites as a function of UV-C light. Anthocyanin concentrations were modified in cranberry water depending on the dose of UV-C light applied $(0,15,30,60,120$ and $240 \mathrm{~mJ} \mathrm{~cm}^{-2}$ ) with a tendency to decrease (10\%) as the dose increased $\left(240 \mathrm{~mJ} \mathrm{~cm}^{-2}\right)$ recommending the UV-C light treatment dose of $40 \mathrm{~mJ} \mathrm{~cm}^{-2}$ [52]. On the other hand, it should be noted that studies related to the sensory preferences of consumers applying different doses UV-C (70, 140 , and $210 \mathrm{~mJ} \mathrm{~cm}^{-2}$ ) on white bread, consumers preferred bread with the dose of $70 \mathrm{~mJ} \mathrm{~cm} \mathrm{~cm}^{-2}$ [70].

In the present investigation, the doses of UV-C radiation applied to bread were lower $\left(0,10.5,21,42 \mathrm{~mJ} \mathrm{~cm}^{-2}\right)$, where at the dose of around $40 \mathrm{~mJ} \mathrm{~cm}^{-2}$, it inhibited some of the phenolic acids in the bread added with turmeric (sinapic, beta resorcylic, syringic, and ferulic). Thus, in our study, the dose of $42 \mathrm{~mJ} \mathrm{~cm}{ }^{-2}$ is not recommended in bread samples due to that it degrades the bread in its phenolic compouds. The applied dose that implies intensity and time of exposure to radiation by UV-C light, influence the percentage of modification of secondary metabolites depending on the type of metabolite studied and the food sample used. In this case, there were phenolic acids that degrade more easily under the applied UV-C light and others were more resistant. Likewise, there are other types of secondary metabolites that are affected. In pomegranate juice exposed to UV-C, they modified secondary metabolites (anthocyanins) in the order of 8-16\% [71]. Even though some international organizations have authorized the use of UV radiation to control organisms [72], it is also important to consider the importance of applying the appropriate doses to food, which avoids degradation of nutrients, as antioxidants, as this research has shown.

It would be convenient not to exceed $21 \mathrm{mJcm}^{-2}$ of UV-C radiation since with higher radiation the stability of phenolic acids decreases and then the addition of turmeric in the bread would decrease its benefits. Which would not be convenient to decrease since the concentration of phenolic compounds is linked to antioxidant activity and beneficial therapeutic effects to people. Therefore, the appropriate irradiation parameters must be reached where its nutritional characteristics are preserved: in this case they could be improved since it is another of the effects reported in the scientific literature.

In fresh fruits, in the postharvest stage, radiated by UV-C, the content of secondary metabolites such as resveratrol increased, the authors reported a change in resveratrol concentration from $1 \mathrm{mg}$ to 2 or $3 \mathrm{mg}$ due to UV-C radiation [73]. In this way, depending on the radiated food and the radiation parameters, oxidation processes or not of secondary metabolites have been found. [74] reported degradation of phenolic compounds as a function of time of exposure 
to UV-C treatment. In the present investigation there were some phenolic acids that remained more stable under UV-C radiation, mainly protocatechuic, p-hydroxybenzoic and gallic acids. These phenolic acids existed in bread without and with turmeric, i.e., are phenolic acids from wheat flour and not due to the addition of turmeric.

Some authors have reported that the main phenolic compounds in grain are concentrated in the bran fraction [75, 76], one of those reported in abundance being ferulic acid. These acids in this investigation were not identified in white bread. Being only identified in bread added with turmeric, although it is not very stable against UV-C radiation since, after $30 \mathrm{~s}$, said phenolic compound disappears in the bread. Other authors have identified this ferulic acid in wheat germ [77], in our research in white bread said phenolic compound was not identified.

The absence of this phenolic compound and others; with a respective change in antioxidant capacity could be due to the thermal process carried out for the preparation of bread and the fermentation time, among other factors $[78,79]$. On the other hand, it should be noted that these wheat compounds are associated with genetics and growing environment in the pre-sowing, sowing, and harvesting stages. These are a function of the genotype used and the associated diseases in its growth process [80]. As is known in the literature, secondary metabolites are modified by various stress conditions to which plants are exposed during their growth [18].

So, the characteristics of the wheat used to produce flour and its production process and later bread are relevant; due to these is the type and concentration level of secondary metabolites found in white bread; which is known for its low antioxidant level [81].

In this way, in the literature and in some countries commercially, fortified breads are proposed or consumed to enrich nutrients and increase their antioxidant capacity. When chemicals are not added to preserve it, a serious problem is generated in this industry, due to the concentration of fungi that develop. In this way UV-C light has been proven as an alternative to reduce fungi in bread. Although it has not only been proposed to sterilize bread in problems in the industry, but also to keep product lines in good sanitary condition. Kawaguchi (2019) [70] found that the most abundant and common fungus in bread is penicillium $\mathrm{sp}$. In the application of this physical method, there is the problem that on the one hand the food product can be healthily benefited; but on the other hand, some nutritional components could be degraded. In our investigation, from the dose of $21 \mathrm{~mJ} \mathrm{~cm}^{-2}$, syringic and ferulic acids, which are important in human health, were degraded.

In the case of ferulic acid, it has a wide range of therapeutic effects against various diseases such as cancer, diabetes, cardiovascular and neurodegenerative due to its strong antioxidant activity. It has also been reported to be an effective free radical scavenger and has been approved in certain countries as a food additive to prevent lipid peroxidation. Indeed, it removes superoxide anion radical and inhibits lipid peroxidation [72].

In the present investigation, the importance of having the appropriate radiation parameters is pointed out since it was demonstrated that UV-C radiation affects the stability of phenolic compounds in white bread and added with turmeric. Although there is also evidence of the positive effect of UV-C treatment in increasing the nutraceutical properties of food [82]. In this research was pointed the need for found dose of radiation depending on the food, i.e., find UV-C dose values that do not cause hormesis.

The need to find adequate doses of UV-C radiation to increase other types of micronutrients through UV-C has been reported. In bread (made with yeast), the phenomenon that occurs through UV-C radiation has been used to convert ergosterol to vitamin $D_{2}$ [83], to increase its level. The illumination time used for UV light (100-400 nm) can be from $0.1-60 \mathrm{~s}$, or $2-30 \mathrm{~s}$ of treatment with UV light. Antimicrobial effects at the wavelength of $254 \mathrm{~nm}$ corresponding to UV-C light have been reported [84]. Vitamin $\mathrm{D}_{2}$ in bread increases due to UV light from 0.75 to $3 \mu \mathrm{g} / 100 \mathrm{~g}$ in UV-treated bread, $1-5 \mathrm{~g} / 100 \mathrm{~g}$ of yeast in the dough. In this way, in the bakery industry this type of environmentally friendly and possibly beneficial applications is important, for the food production and storage process in the best possible conditions in the different quality, microbiological and nutritional attributes. Just as there is a tendency to increase some components of bread due to UV-C light, it can also decrease, at least in the case of the phenolic acids identified in this research. Similarly, it was reported by other authors in different types of food with doses around $200 \mathrm{~mJ} \mathrm{~cm}^{-2}$ $[85,86]$.

This behavior results of phenolic acids are visualized in Figs. 3 and 4. Figure 3, represents the behavior of each type of phenolic acid, for each type of bread at each level of UV-C radiation $(0,15,30$ and $60 \mathrm{~s})$ applied. The horizontal axis represents the breads added with different percentages of turmeric (A, B, C, D and E). The left vertical axis marked from numbers 1 to 8 refer to the types of phenolic acids identified in the bread samples (1. Sinapic, 2. Beta resorcylic, 3. Syringic, 4. Chlorogenic, 5. Ferulic, 6. Protocatechuic, 7. p-hydroxybenzoic and 8. Gallic) in the loaves and on the right side is their content $(\mu \mathrm{g} / \mathrm{mL})$. Phenolic acids 6,7 and 8 did not degrade due to UVC radiation.

Figure 4 shown that three groups of breads have been formed according to their content of the various secondary metabolites, group I (Quadrant I and II: 60 A, B, C, D, E; 30 B, C, D, E and 0 A), Group II (Quadrant III: 0 B, C, D, E; 15 A, B, C, D, E and 30 A) and Group 3 (Quadrant IV: $15 \mathrm{E}$ ). It can be observed that beta resorcyclic, sinapic and syringic acid are correlated and show higher levels 
Fig. 3 Concentration of phenolic acids in different percentages of Curcuma Longa L. added to box bread and exposed to different times of UV light $(0,15,30$ and $60 \mathrm{~s}) .1$. Sinapic acid 2. Beta resorcylic acid 3. Syringic acid 4. Chlorogenic acid 5. Ferulic acid 6. Protocatechuic acid 7. p-hydroxybenzoic 8.Gallic acid. A. 0\% (control) B. $1.25 \%$ C. $2.50 \%$ D. $5 \%$ E. $10 \%$
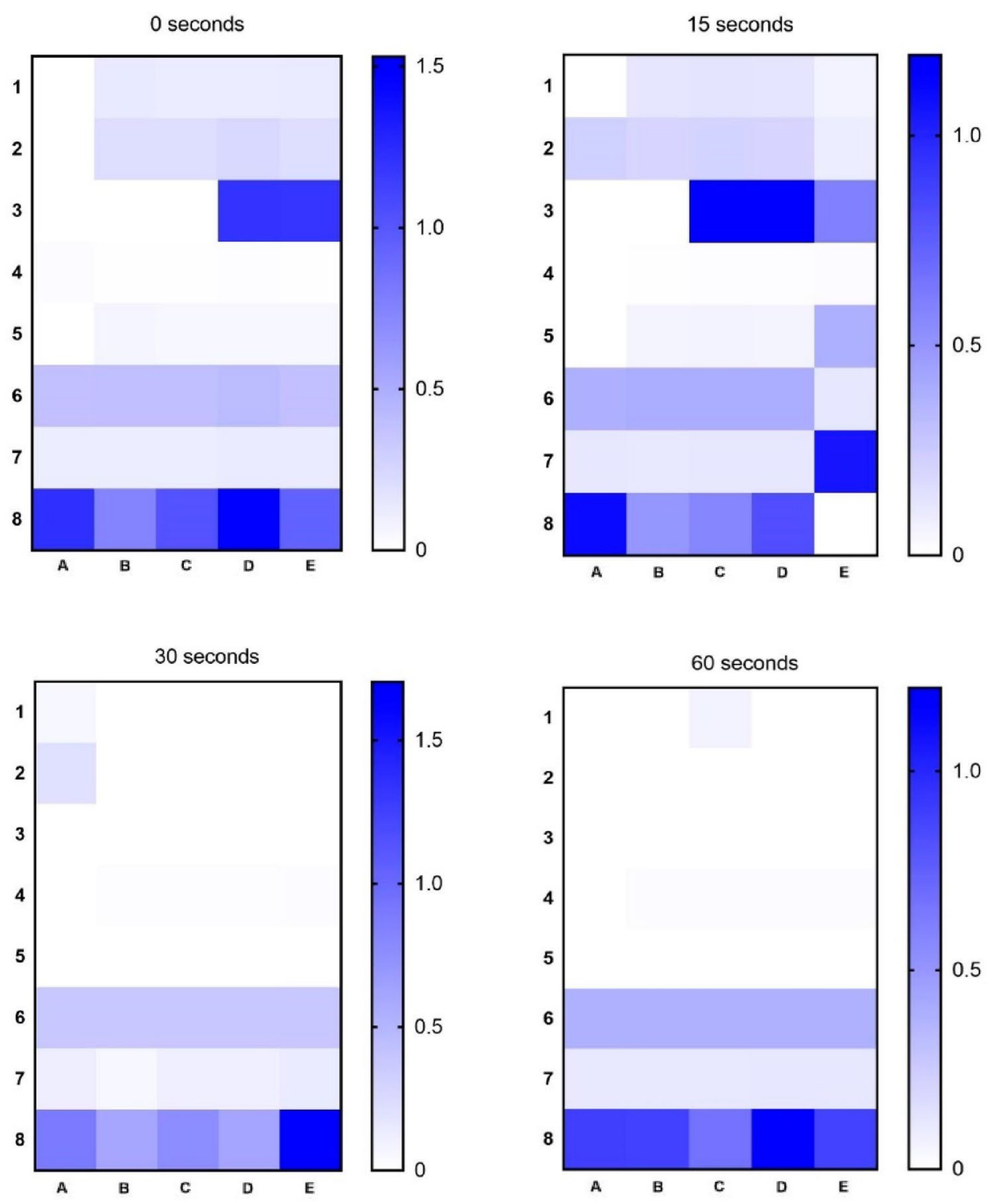

of these metabolites $15 \mathrm{~A}, 30 \mathrm{~A}, 0 \mathrm{C}$ and $0 \mathrm{D}$ (Fig. 2). In contrast, panes $60 \mathrm{~A}, \mathrm{~B}, \mathrm{C}, \mathrm{D}, \mathrm{E}$ and $30 \mathrm{~A}, \mathrm{~B}, \mathrm{C}, \mathrm{D}, \mathrm{E}$ and $0 \mathrm{~A}$, is related to lower levels of these phenolic acids. Furthermore, it can be observed that ferulic acid was more abundant in breads $0 \mathrm{~B}, \mathrm{E}$ and $15 \mathrm{~B}, \mathrm{C}, \mathrm{D}, \mathrm{E}$; the highest value being bread $15 \mathrm{E}$. In contrast, bread $30 \mathrm{~A}, \mathrm{~B}, \mathrm{C}, \mathrm{D}$, $\mathrm{E}$ and $60 \mathrm{~A}, \mathrm{~B}, \mathrm{C}, \mathrm{D}$ and $\mathrm{E}$, which is situated at the other side of the plot, is related to lower levels, in this specific case there was no existence of ferulic acid.

The found phenolic acid derivatives are classified according to [54] as hydroxybenzoic (beta resorcylic, syringic, protocatechuic, p-hydroxybenzoic, gallic) and hydroxycinnamic (sinapic, chlorogenic, ferulic). The concentration of phenolic acids in box bread made with different percentages of curcuma Longa L are modified depending on the percentage of curcuma and the exposure times to $\mathrm{UV}-\mathrm{C}$ radiation. Each phenolic compound responds differently.

\section{Color and proximate chemical analysis}

ANOVA results, for the proximate chemical (Moisture, protein, fat, ash, fiber) and color (L, a, b) parameters, revealed significant differences $(\mathrm{P}<0.05)$ between breads made at different turmeric concentrations and radiation levels (Table 3). In the bread added with turmeric, the percentage of moisture increased as the turmeric concentration increased. This can be seen that there was a significant increase of $10.2 \%$ when comparing bread at $10 \%$ turmeric and control bread (without TP). Protein, fat, ash, and fiber increased by 13.76, 31.57, 27.97 and $11.41 \%$. It should be noted that some authors have reported in the characterization of turmeric powder 


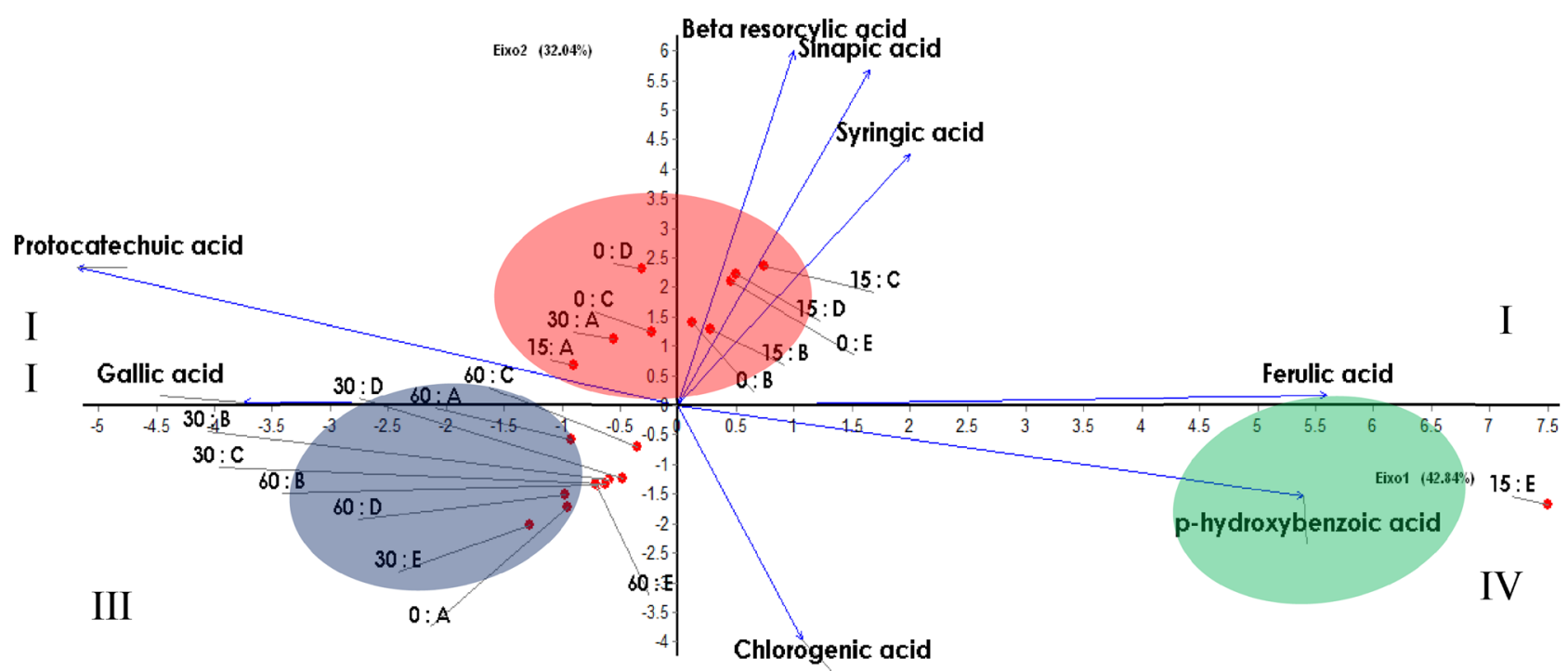

Fig. 4 Principal component analysis of box bread added with turmeric $(0,1.25,2.5,5$ and 10\%) exposed to different times of UV light ( $0,15,30$ and $60 \mathrm{~s}$ ), according to the concentration of phenolic acids

Table 3 Chemical and color analysis of bread with different percentage of turmeric exposed to different times of radiation (UV-C)

\begin{tabular}{|c|c|c|c|c|c|c|c|c|c|}
\hline \multirow{2}{*}{$\begin{array}{l}\text { Time } \\
\text { (sec- } \\
\text { onds)* }\end{array}$} & \multicolumn{6}{|c|}{ Proximal Chemistry } & \multicolumn{3}{|c|}{ Color measurements } \\
\hline & Treatment & Moisture \% & Protein $\%$ & Fat $\%$ & Ash \% & Fiber $\%$ & $\mathrm{~L}^{*}$ & $a^{*}$ & $b^{*}$ \\
\hline \multirow[t]{5}{*}{ I. 0} & $\begin{array}{c}\text { A. } 0 \% \\
\text { (con- } \\
\text { trol) }\end{array}$ & $9.8 \pm 0.08^{\mathrm{c}}$ & $22.15 \pm 0.25^{\text {gih }}$ & $10.04 \pm 0.09^{\mathrm{kj}}$ & $1.68 \pm 0.01^{\mathrm{i}}$ & $3.68 \pm 0.08^{\mathrm{fgh}}$ & $58.85 \pm 2.70^{\mathrm{a}}$ & $1.47 \pm 0.12^{\mathrm{e}}$ & $14.87 \pm 0.28^{\mathrm{ij}}$ \\
\hline & B. $1.25 \%$ & $8.71 \pm 0.09^{\mathrm{d}}$ & $21.87 \pm 0.47^{j}$ & $11.00 \pm 0.12^{\mathrm{i}}$ & $1.71 \pm 0.05^{\mathrm{i}}$ & $3.37 \pm 0.08^{\text {ih }}$ & $56.88 \pm 0.33^{b}$ & $1.46 \pm 0.35^{\mathrm{e}}$ & $45.51 \pm 0.30^{\mathrm{gf}}$ \\
\hline & C. $2.5 \%$ & $8.21 \pm 0.12^{\mathrm{e}}$ & $24.14 \pm 0.10^{\mathrm{ed}}$ & $10.36 \pm 0.20^{j}$ & $1.8 \pm 0.04^{\mathrm{fg}}$ & $5.1 \pm 0.16^{\mathrm{a}}$ & $46.30 \pm 5.36^{\mathrm{d}}$ & $12.48 \pm 4.7^{\mathrm{c}}$ & $57 \pm 2.86^{\mathrm{fdec}}$ \\
\hline & D. $5 \%$ & $8.46 \pm 0.15^{\mathrm{ed}}$ & $24.94 \pm 0.06^{\mathrm{c}}$ & $12.14 \pm 0.10^{\mathrm{f}}$ & $2.06 \pm 0.0^{\mathrm{bc}}$ & $3.99 \pm 0.19^{\mathrm{fde}}$ & $41.59 \pm 1.17^{\mathrm{f}}$ & $20.83 \pm 1.68^{b}$ & $61.68 \pm 4.43^{\text {bdec }}$ \\
\hline & E. $10 \%$ & $10.80 \pm 0.06^{\mathrm{a}}$ & $25.2 \pm 0.06^{\mathrm{ba}}$ & $13.21 \pm 0.14^{\mathrm{d}}$ & $2.15 \pm 0.07^{\text {ba }}$ & $4.1 \pm 0.12^{\mathrm{cd}}$ & $43.46 \pm 0.46^{\text {edf }}$ & $26.20 \pm 1.22^{\mathrm{a}}$ & $72.27 \pm 2.68^{\mathrm{ba}}$ \\
\hline \multirow[t]{5}{*}{ II. 15} & $\begin{array}{l}\text { A. } 0 \% \\
\text { (con- } \\
\text { trol) }\end{array}$ & $6.17 \pm 0.13 \mathrm{j}$ & $22.12 \pm 0.06 \mathrm{i}$ & $9.86 \pm 0.12^{\mathrm{k}}$ & $1.76 \pm 0.05^{\text {ih }}$ & $3.32 \pm 0.14^{\mathrm{i}}$ & $61.58 \pm 1.29^{\mathrm{a}}$ & $1.53 \pm 0.21 \mathrm{e}$ & $14.62 \pm 0.57 \mathrm{ij}$ \\
\hline & B. $1.25 \%$ & $4.12 \pm 0.21 \mathrm{~m}$ & $22.16 \pm 0.09 \mathrm{ih}$ & $11.7 \pm 0.13 \mathrm{~g}$ & $1.9 \pm 0.05 \mathrm{fg}$ & $4.14 \pm 0.13 \mathrm{~cd}$ & $46.22 \pm 3.98 \mathrm{~d}$ & $3.42 \pm .71 \mathrm{e}$ & $26.33 \pm 2.29 \mathrm{ih}$ \\
\hline & C. $2.5 \%$ & $4.55 \pm 0.21^{\mathrm{L}}$ & $24.22 \pm 0.08^{\mathrm{d}}$ & $14.97 \pm 0.21^{\mathrm{a}}$ & $1.9 \pm 0.04^{\mathrm{efg}}$ & $4.62 \pm 0.19^{b}$ & $45.90 \pm 1.64 \mathrm{ed}$ & $11.55 \pm 0.64 \mathrm{dc}$ & $53.23 \pm 2.57$ gfde \\
\hline & D. $5 \%$ & $8.29 \pm 0.13^{\mathrm{e}}$ & $24.86 \pm 0.12^{c}$ & $10.95 \pm 0.55^{\mathrm{i}}$ & $2.00 \pm 0.05^{\mathrm{ecd}}$ & $3.99 \pm 0.11 \mathrm{fde}$ & $41.66 \pm 1.56 \mathrm{f}$ & $20.99 \pm 0.26 b$ & $63.43 \pm 0.33$ bdac \\
\hline & E. $10 \%$ & $7.2 \pm 0.03 \mathrm{~g}$ & $24.98 \pm 0.13^{b c}$ & $13.63 \pm 0.27^{\mathrm{c}}$ & $2.14 \pm 0.04^{\mathrm{ba}}$ & $4.35 \pm 0.17 \mathrm{cb}$ & $42.08 \pm 0.37$ ef & $24.61 \pm 0.06 \mathrm{a}$ & $66.74 \pm 1.79 \mathrm{bac}$ \\
\hline \multirow[t]{5}{*}{ III. 30} & $\begin{array}{l}\text { A. } 0 \% \\
\text { (con- } \\
\text { trol) }\end{array}$ & $6.95 \pm 0.18 \mathrm{hj}$ & $22.45 \pm 0.20 \mathrm{gf}$ & $10.01 \pm 0.21 \mathrm{j}$ & $1.72 \pm 0.02 \mathrm{i}$ & $4.05 \pm 0.08 \mathrm{cde}$ & $61.79 \pm 0.83 \mathrm{a}$ & $1.54 \pm .23 \mathrm{e}$ & $14.49 \pm 1.14 \mathrm{ij}$ \\
\hline & B. $1.25 \%$ & $5.97 \pm 0.40 \mathrm{j}$ & $22.37 \pm 0.06 \mathrm{gh}$ & $11.26 \pm 0.28 \mathrm{hi}$ & $1.96 \pm 0.05$ ef & $4.59 \pm 0.34 b$ & $54.51 \pm 3.19 \mathrm{cb}$ & $1.48 \pm 1.13 \mathrm{e}$ & $42.99 \pm 0.70 \mathrm{~g}$ \\
\hline & C. $2.5 \%$ & $3.96 \pm 0.18 \mathrm{~m}$ & $23.95 \pm 0.05 \mathrm{e}$ & $14.44 \pm 0.34 \mathrm{~b}$ & $1.92 \pm 0.02$ efg & $4.66 \pm 0.21 b$ & $41.44 \pm 2.94 \mathrm{f}$ & $13.48 \pm 4.05 \mathrm{c}$ & $55.17 \pm 5.15$ gfdec \\
\hline & D. $5 \%$ & $6.63 \pm 0.29 \mathrm{i}$ & $25.08 \pm 0.09 \mathrm{bac}$ & $11.29 \pm 0.18 \mathrm{hi}$ & $2.06 \pm 0.03 \mathrm{bcd}$ & $3.74 \pm 0.18$ fge & $41.84 \pm 0.49$ ef & $21.37 \pm 1.58 b$ & $63.73 \pm 2.99$ bdac \\
\hline & E. $10 \%$ & $6.70 \pm 0.05 \mathrm{hi}$ & $25.25 \pm 0.05 \mathrm{a}$ & $12.45 \pm 0.17 \mathrm{fe}$ & $2.10 \pm 0.06 \mathrm{ba}$ & $4.37 \pm 0.30 \mathrm{cb}$ & $41.90 \pm 1.50$ ef & $26.73 \pm 0.52 \mathrm{a}$ & $74.61 \pm 0.15 \mathrm{a}$ \\
\hline \multirow[t]{5}{*}{ IV. 60} & $\begin{array}{l}\text { A. } 0 \% \\
\text { (con- } \\
\text { trol) }\end{array}$ & $7.20 \pm 0.12 \mathrm{~g}$ & $22.52 \pm 0.06 \mathrm{f}$ & $10.27 \pm 0.06 \mathrm{j}$ & $1.92 \pm 0.17$ efg & $3.62 \pm 0.16$ igh & $55.25 \pm 4.69 \mathrm{cb}$ & $1.83 \pm 048 \mathrm{e}$ & $13.49 \pm 1.54 \mathrm{j}$ \\
\hline & B. $1.25 \%$ & $6.65 \pm 0.23 \mathrm{hi}$ & $24.02 \pm 0.12 \mathrm{ed}$ & $11.12 \pm 0.34 \mathrm{hi}$ & $1.8 \pm 0.05 \mathrm{hg}$ & $4.56 \pm 0.29 b$ & $52.62 \pm 4.3 \mathrm{c}$ & $1.72 \pm 0.70 \mathrm{e}$ & $27.69 \pm 20.98 \mathrm{~h}$ \\
\hline & C. $2.5 \%$ & $5.54 \pm 0.42 \mathrm{k}$ & $24.22 \pm 0.09 \mathrm{~d}$ & $11.46 \pm 0.18 \mathrm{hg}$ & $1.94 \pm 0.03$ efg & $3.44 \pm 0.21 \mathrm{igh}$ & $46.66 \pm 4.22 \mathrm{~d}$ & $9.33 \pm 1.81 \mathrm{~d}$ & $49.87 \pm 0.38$ gfe \\
\hline & D. $5 \%$ & $10.47 \pm 0.05 b$ & $25.10 \pm 0.09 \mathrm{bac}$ & $15.13 \pm 0.19 \mathrm{a}$ & $1.93 \pm 0.03$ efd & $4.67 \pm 0.22 b$ & $40.65 \pm 0.24 \mathrm{f}$ & $21.45 \pm 1.01 \mathrm{~b}$ & $64.50 \pm 3.36$ bdac \\
\hline & E. $10 \%$ & $7.71 \pm 0.02 \mathrm{f}$ & $25.26 \pm 0.10 \mathrm{a}$ & $12.76 \pm 0.15 \mathrm{e}$ & $2.17 \pm 0.03 \mathrm{a}$ & $4.06 \pm 0.26 \mathrm{cde}$ & $42.87 \pm 1.11 \mathrm{edf}$ & $25.94 \pm 1.74 \mathrm{a}$ & $73.35 \pm 3.70 \mathrm{ba}$ \\
\hline
\end{tabular}

The different letters in the columns indicates that the values are statistically different $(p \leq 0.05)$ 
the existence of protein, fat, and fiber (Castro, 2016) [87]. Therefore, when added to bread, its values are increased. As well as others report its high antioxidant capacity due to the existence of phenols and carotenoids (Hernández et al. 2020a) [35]. Thus, bread added with turmeric has been reported as a functional food, given its therapeutic properties due to the bioactive elements that compose it.

The moisture percentage (MP) is modified due to radiation, presenting a tendency to decrease. When comparing the MP values of the bread added $10 \%$ (TP) and control bread (without TP), a higher decrease of MP (37.96\%) was obtained at the radiation time of the bread of $30 \mathrm{~s}$.

Other authors reported effect of UVC treatments on moisture content of samples. The reduction of moisture percentage among other causes, has been attributed to the soft heating due to the application of UVC irradiation, that could increase the temperature (Demirci and Krishnamurthy, 2011) [88]. This radiation heating effect has been reported at long exposure times (30 and $120 \mathrm{~min}$ ). In the present investigation, in the case of bread samples without curcuma, the moisture content was decreased after $15 \mathrm{~s}$ of exposure to UVC light. It is worth noting that the instrumentation used included four lamps of $30 \mathrm{~W}$ each.

Regarding, the amount of protein in turmeric bread $(1.25 \%)$ increased $(9.8 \%)$ at $60 \mathrm{~s}$ radiation. However, in fat, ash, and fiber the relevant changes in the bread were due to the addition of turmeric and not to UV-C radiation.

The behavior of the color characteristics (coordinates $\mathrm{L}^{*}, \mathrm{a}^{*}, \mathrm{~b}^{* *}$ varied significantly $(\mathrm{P}<0.05)$ as a function of the concentration of turmeric added to the bread (Table 3 ). Brightness coordinate $\left(\mathrm{L}^{*}\right)$ decreased $(26.15 \%)$ and redness $\left(a^{*}\right)$ and yellowness $\left(b^{*}\right)$ increased more than $100 \%$ when turmeric was added to bread (A). The highest values were related to the yellowness of the bread $\left(b^{*}\right)$, consistent with the yellow color of the bread added with turmeric; whose yellow color is associated with curcuminoids, which are one of the most important compounds found in turmeric. Together with phenolic acids and flavonoids, they have been associated with beneficial effects on human health (VidalCasanella et al., 2020) [89].

Other studies have reported that the color coordinate of yellowness $\left(b^{*}\right)$ had a highly positive correlation with lutein, $\beta$-cryptoxanthin and $\beta$-carotene levels, as well as with the level of total carotenoids (Kljak et al., 2014) [90]. Similarly, other studies on yellow food products have found $b^{*}$ to be related to carotenoid content (Meléndez-Martínez et al., 2003) [91].

Other authors have reported modification of the $b^{*}$ color component due to UV-C radiation. Semolina used to make bread dough was treated with UV-C irradiation for 5, 15, 30 and $120 \mathrm{~min}$. The UV-C treatment caused some changes in the color of the bread, mainly in the $\mathrm{b}^{*}$ color coordinate. The treated samples had a value in the order of 19.2-19.7 and the control samples 17.6, there being an increase in this color yellowness component of approximately 10\% (Campagna et al., 2020) [47]. In the present investigation, the exposure times of the bread were shorter, and no significant changes were found in the components due to radiation. The changes found were due to the addition of turmeric in the bread.

\section{Sensory analysis}

Table 4 shows the comparison of means between the sensory variables (color, porosity, hardness, aroma, stickiness, chewiness, flavor, healthy option, general attribute) evaluated for the different types of bread. It is possible to observe that there were differences between these, in relation to the color attribute, the bread preferred by the consumer evaluators was the $1.25 \%$ turmeric bread (TP), with ratings for each radiation applied (I, II, III, IV), respectively $(8.33,8.66$, $8.66,9)$, followed by white bread and bread with $2.5 \%$ turmeric addition. The acceptance of the bread in the flavor attribute decreased with increasing turmeric concentration when compared to wheat bread ( $0 \%$ of TP), mainly for the bread at 5 and $10 \%$ addition (12 and 24.0\%). Flavor was not affected due to UVC radiation, except for the bread at $10 \%$ turmeric addition and $60 \mathrm{~s}$ of radiation, which decreased its preference by $48 \%$.

For the aroma attribute, it was evaluated at a higher score for wheat bread without turmeric powder $(0 \% \mathrm{TP})$, with the scores for the different radiation times (I, II, II, IV), of (5.66, $6.33,7.33,7.33,7.33)$. It should be noted that bread preference according to this attribute decreased as the concentration of curcuma added to the bread increased. But the ratings improved with the radiation of the bread, that is, the bread aroma is modified by UVC radiation. The odor produced by the curcuma added to the bread decreased. In this case, this could be an advantage to increase acceptance of bread added with turmeric at a higher concentration of turmeric. Other authors, in other types of food when non-thermal methods are applied, do not want to alter the aroma and flavor of the food [92].

The breads with the best acceptance for their healthy characteristics were the turmeric breads when compared to the control bread ( $0 \%$ of TP) with more than $92 \%$ preference. In relation to the attributes generally rated, it is possible to observe that the breads generally preferred are the $1.25 \%$ and $2.5 \%$ breads. It is important to point out that the people evaluated are aware of choosing healthy foods, according to Covid-19 times. These results indicate that the turmeric bread option would be a healthy type of bread that people might choose to consume. In general, there is a tendency to opt for healthy breads for the sake of health. Many of the times, the way they choose is due to people's healthy awareness or because of an associated disease in themselves or their family members (e.g., diabetes, Covid-19, 


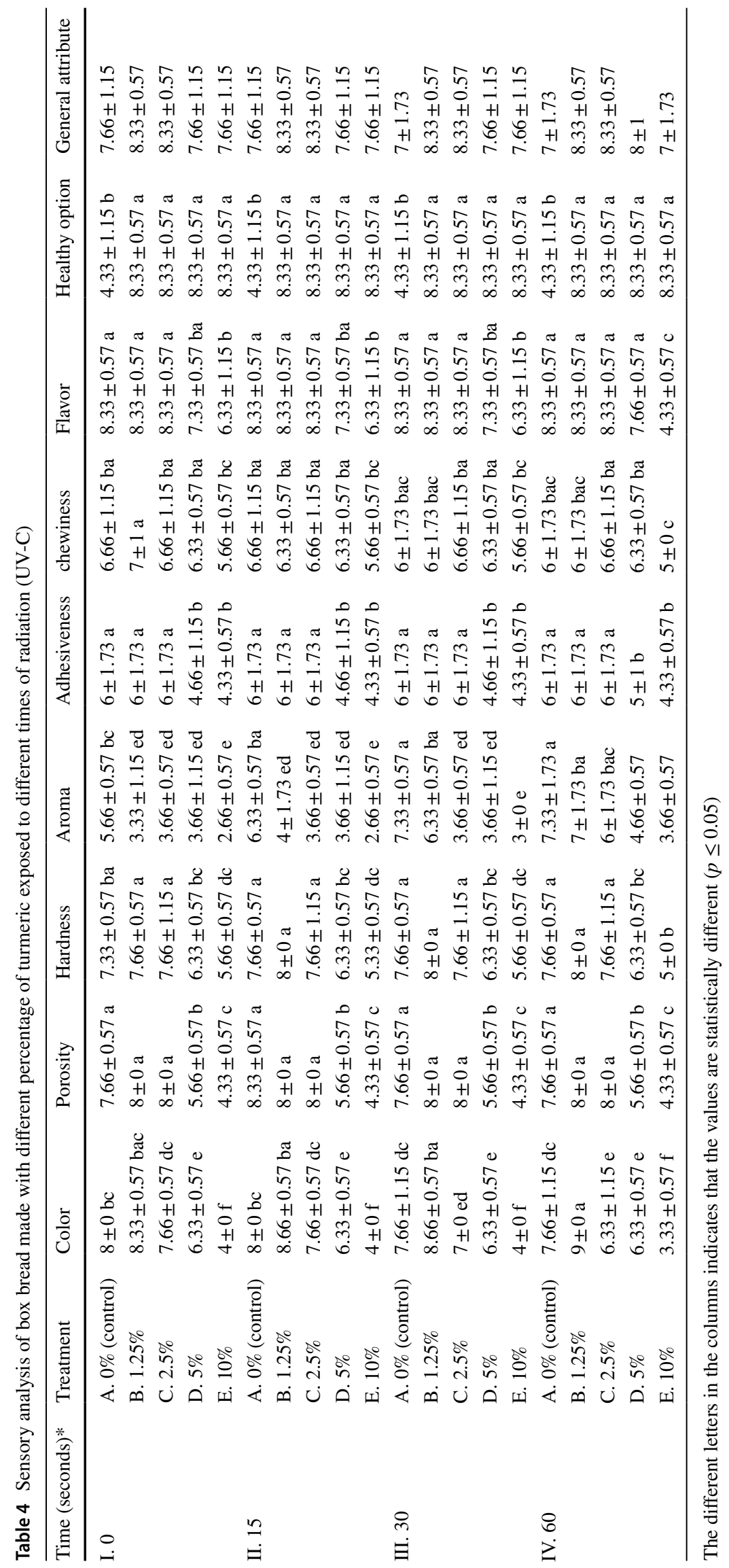


hypertension). The results of this research coincide with other reports where a decrease in sensory preference has also been found, mainly for bread flavor or color, but when health is a priority, people choose breads that use some bioactive element added to the bread, because of the health benefits

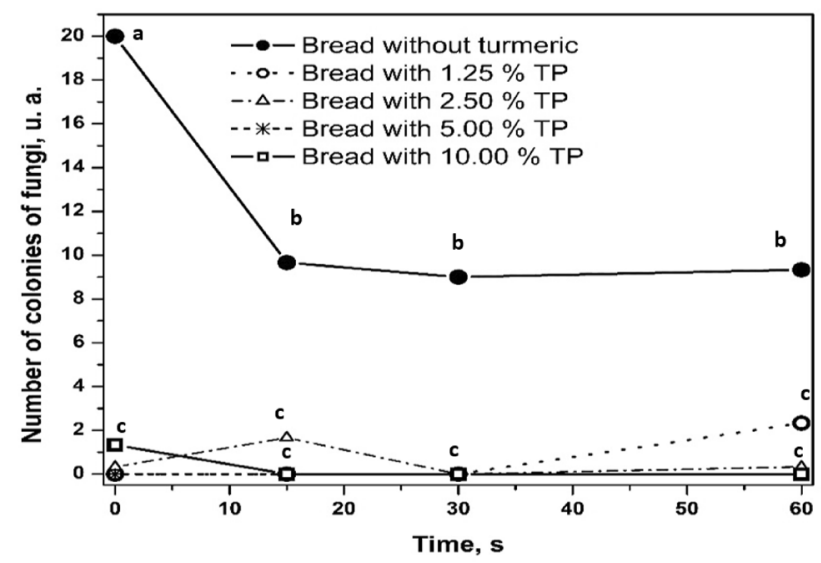

Fig. 5 Antifungal effects of turmeric and UVC radiation it could provide $[35,62,66]$. In developing countries, the example of Japan could be implemented, where green tea powder (matcha) is added to many of the food products consumed, including the bread [93].

\section{Fungal effects}

Sanitary quality test was established and evaluated after seven days, the control bread ( $0 \% \mathrm{TP})$ without UV-C radiation was found to be the most contaminated (Fig. 5). This was followed by the control bread (without curcuma) with UV-C radiation treatment. It is possible to observe a decrease in the number of fungal colonies of more than $50 \%$ in the irradiated bread compared to the non-irradiated bread, from the radiation time of $15 \mathrm{~s}$. The fungi found in the bread slices were mainly Penicillium sp. (growing colonies in green color with dense conidia). Thus, UV-C radiation applied to white bread (according to the formulation described in the present investigation) decreases the number of fungal colonies (Table 5).

Likewise, in the present investigation, the addition of turmeric inhibited the development of fungi in percentages

Table 5 Bread making input and service costs (Color Table online)

\begin{tabular}{|c|c|c|c|c|c|c|c|c|c|c|}
\hline \multirow{2}{*}{$\begin{array}{l}\text { Treatments Dif- } \\
\text { ferent \% of TP }\end{array}$} & \multicolumn{10}{|l|}{ Cost in dollars } \\
\hline & Bread digital image & Wheat Flour & Olive oil & Egg & Salt & Sugar & Yeast & $\begin{array}{l}\text { Turmeric } \\
\text { powder }\end{array}$ & Water & Total 21 slices \\
\hline \multicolumn{11}{|l|}{ Supplies } \\
\hline A). CB (0 g) & & 0.41 & 0.99 & 0.13 & 0.004 & 0.005 & 0.16 & 0 & 0.11 & 1.8 \\
\hline $\begin{array}{l}\text { B). TB-1.25\% } \\
(7.5 \mathrm{~g})\end{array}$ & & 0.41 & 0.99 & 0.13 & 0.004 & 0.005 & 0.16 & 0.11 & 0.11 & 1.9 \\
\hline $\begin{array}{l}\text { C). TB-2.5\% } \\
(15 \mathrm{~g})\end{array}$ & & 0.40 & 0.99 & 0.13 & 0.004 & 0.005 & 0.16 & 0.22 & 0.11 & 2.01 \\
\hline $\begin{array}{l}\text { D). TB-5.0\% } \\
(30 \mathrm{~g})\end{array}$ & & 0.39 & 0.99 & 0.13 & 0.004 & 0.005 & 0.16 & 0.44 & 0.11 & 2.22 \\
\hline $\begin{array}{l}\text { E). TB-10 } \\
(60 \mathrm{~g})\end{array}$ & & 0.37 & 0.99 & 0.13 & 0.004 & 0.005 & 0.16 & 0.89 & 0.11 & 2.65 \\
\hline \multicolumn{11}{|c|}{ Services and fixed investment } \\
\hline Baker's labor & & & & & & & & & & 4.98 \\
\hline Electric power & & & & & & & & & & 0.39 \\
\hline Blender & & & & & & & & & & 184.4 \\
\hline Electric oven & & & & & & & & & & 299 \\
\hline Electric knife & & & & & & & & & & 42.38 \\
\hline
\end{tabular}

TP Turmeric powder, TB Turmeric bread

Turmeric powder was incorporated in A: 600, B: 592.5, C: 585, D: 570 and E: $540 \mathrm{~g}$ of wheat flour weight 
higher than $88 \%$ in irradiated and non-irradiated bread. In the non-irradiated bread, no fungal colonies were observed after $1.25 \%$ addition of turmeric. However, at the highest turmeric concentration (10\%) there tended to be fungal growth.

In the turmeric bread irradiated by UV-C ( $30 \mathrm{~s})$ in the different concentrations, no fungus colonies formed seven days after the sanitary test was established.

However, bread at a UV-C radiation exposure time of $60 \mathrm{~s}$, the appearance of a small number of fungal colonies can be appreciated for turmeric concentrations of $(0,1.25$ and $2.5 \%$ ) of $9.33 \pm 2.88,2.33 \pm 4.9$ and $0.33 \pm 0.7$. In Fig. 5, it is clearly observed how the number of fungi developed in the bread (after seven days of incubation of these) due to the radiation of bread from the exposure time of $15 \mathrm{~s}$ is decreased.

Likewise, it is observed that by the addition of turmeric for all types of bread (including non-irradiated bread) the amount of fungal colony developed is reduced; despite the increase of humidity in the bread produced by the addition of turmeric in the bread. This demonstrates the fungal potential of both UV-C treatment of bread and how the addition of turmeric impacts on improving the sanitary quality of the bread. The best results in bread sanitary quality were found in all breads added with turmeric. This coincides with what has been recently reported by other authors, where they also report an antifungal and fungistatic power of turmeric, that is, the ability to inhibit and/or delay the appearance of fungi in bread [35]. This is associated with its bioactive components called curcuminoids where curcumin is included [94]. Thus, this type of bread has relevant aspects that make it a type of functional bread for these times of Covid-19, adding to a type of food for the present and the future.

\section{Economic study}

Table 5 shows the costs in dollars for each input used to make the different types of bread at the respective formulation (Table 1). The current prices of the inputs needed to make bread in Mexico City are below the dollar, most of them less than half a dollar, except for olive oil (extra virgin), which turned out to be the most expensive ingredient, due to the quantity added $(70 \mathrm{~g})$, which raises the cost of the bread. Due to the poor absorption and rapid metabolism in the organism of curcumin, a bioactive element of curcuma, olive oil was added in this research. Since, in relation to the inputs to make bread, it is the element that produces the greatest increase in the price of bread. In the literature it is recommended to add a phospholipid or pepper to improve bioavailability $[35,95]$. Then, an option to reduce the price would be to reduce at least by half the amount of oil that was added in this research and better to add pepper, this would allow a more appropriate price to acquire in the population, since there is a percentage of the same low-income population that could not buy high priced bread as it is a basic product of daily consumption. According to the inputs and quantities used in this research, it is observed that to make turmeric bread (considering only inputs) would range between 1.9-2.65 dollars (cost for one piece of turmeric bread, of which we could obtain 21 slices). This is observed, the price rises as the amount of turmeric added increases, the higher the concentration of turmeric, the higher the price. But we must consider that according to the sensory preferences of people and the results found beneficial to inhibit the growth of fungi, it could be done by adding turmeric concentrations from $1.25,2.5$ to $5 \%$. It should be noted that in this research people evaluated a preference to decide based on how healthy bread can be, but it is important to mention that all people belong to an economic level that allows them to acquire products higher than the common price of a basic food basket. The price of the basic food basket in Mexico for urban and rural areas is 88.70 and 67.85 dollars, according to the National Council for the Evaluation of Social Development Policy (CONEVAL).

Due the use of harmful chemicals in developing countries, it is important to continue exploring these possibilities offered by physical methods to improve the nutritional and sanitary quality of bread.

\section{Conclusions}

Phenolic acids have been identified in white bread (chlorogenic, protocatechuic, p-hydroxybenzoic and gallic) added with turmeric (sinapic, beta resorcylic, syringic, chlorogenic, ferulic, protocatechuic, p-hydroxybenzoic and gallic). Gallic and protocatechuic has been the most abundant phenolic acid. It was found that with higher UV-C radiation, the concentration level of phenolic acids decreases, being at 0 and $15 \mathrm{~s}$, eight identified phenolic acids and at 30 and $60 \mathrm{~s}$, six and five were found for 30 and $60 \mathrm{~s}$.

Exposure of breads exposed to UV-C radiation duration of $15 \mathrm{~s}$, produced significant statistical differences $(\mathrm{P} \leq 0.05)$ in chlorogenic, ferulic, protocatechuic, p-hydroxybenzoic and gallic acids. The most abundant acids were protocatechuic $(0.394$ and $0.393 \mu \mathrm{g} / \mathrm{mL})$ acid in the samples of bread to B (1.25\%) and C (2.5\%) and gallic (1.1 and $0.8 \mu \mathrm{g} /$ $\mathrm{mL})$ in the samples of breads, $\mathrm{A}(0 \%)$ and $\mathrm{D}(5 \%)$.

The UV-C radiation at $30 \mathrm{~s}$ of exposure of the breads produces statistically significant changes in the chlorogenic, and gallic phenolic compounds, having the maximum values of this type of acid in the breads at $10 \%$ addition of turmeric (reaching values of 0.03 and $1.7 \mu \mathrm{g} / \mathrm{mL}$, respectively).

UV-C radiation during the $60 \mathrm{~s}$ exposure time did not lead to statistically significant changes in any of the constituent phenolic acids of bread at this radiation level (sinapic, 
chlorogenic, protocatechuic, p-hydroxybenzoic and gallic). Beta resorcylic, syringic and ferulic acid were not found in bread at this time of radiation exposure.

In the proximate chemical and color analysis, significant changes in Moisture, protein, fat, ash, fiber, and color ( $\mathrm{L}^{*}$, $\left.a^{*}, b^{*}\right)$ were found in the breads evaluated and were mainly attributed to the addition of curcuma to the bread, except for the changes in moisture which were attributed to both curcuma and UV-C. Turmeric caused moisture to increase with increasing concentration and decrease with radiation.

Regarding sensory analysis, it was found that the bread decreases its preference in the variables due to the increase in the concentration of turmeric. However, people prefer turmeric bread due to the possible health benefits. In the case of the sensory attribute of aroma, it was found to be modified due to UV-C radiation.

Finally, the sanitary quality is improved due to both UV-C radiation and incorporation of turmeric. However, the higher results in the improvement of sanitary quality were due to turmeric.

Acknowledgements Claudia Hernandez thanks the support for SIP (20211699 and 20201809) research projects and to all collaborators

\section{References}

1. FAO, Plan of Action, World Food Summit Roma 26, 244 (1996)

2. M.M. Delorme, J.T. Guimarães, N.M. Coutinho, C.F. Balthazar, R.S. Rocha, R. Silva, L.P. Margalho, T.C. Pimentel, M.C. Silva, M.Q. Freitas, D. Granato, A.S. Sant'Ana, MCKH Duarta, A.G. Cruz, Trends Food Sci Technol. 102, 146 (2020)

3. D.M. Gunter-Ward, A. Patras, M.S. Bhullar, A. Kilonzo-Nthenge, B. Pokharel, M. Sasges, J Food Process Preserv. 42, e13485 (2018)

4. C. Otto, S. Zahn, F. Rost, P. Zahn, D. Jaros, H. Rohm, Food Eng Rev. 3, 171 (2011)

5. N.N.A.K. Shah, R. Shamsudin, R.A. Rahman, N.M. Adzahan, Beverages. 2, 3 (2016)

6. Y.M. Zhao, M. de Alba, D.W. Sun, B. Tiwari, Crit Rev Food Sci Nutr. 59, 728 (2019)

7. C. Jermann, T. Koutchma, E. Margas, C. Leadley, V. Ros-Polski, Innov Food Sci Emerg Technol. 31, 14 (2015)

8. Q. Wang, L. Chu, L. Kou, Sci Hortic. 225, 380 (2017)

9. J.A. Guerrero-Beltran, G.V. Barbosa C Novas, Food Sci Technol Int. 10, 137 (2004)

10. V. Melini, F. Melini, Fermentation. 4, 9 (2018)

11. S. Condón-Abanto, S. Condón, J. Raso, J.G. Lyng, I. Álvarez, Innov Food Sci Emerg Technol. 35, 1 (2016)

12. M. Alothman, R. Bhat, A.A. Karim, Innov Food Sci Emerg Technol. 10, 512 (2009)

13. K.A. Hirneisen, E.P. Black, J.L. Cascarino, V.R. Fino, D.G. Hoover, K.E. Kniel, Compr Rev Food Sci F. 9,3 (2010)

14. T. Yusaf, R.A. Al-Juboori, Appl. Energy 114, 909 (2014)

15. M.S. Islam, A. Patras, B. Pokharel, Y. Wu, M.J. Vergne, L. Shade, H. Xiao, M. Sasges, Innov Food Sci Emerg Technol 34, 344 (2016)

16. H. Frohnmeyer, D. Staiger, Plant Physiol. 133, 1420 (2003)

17. A.R. Vicente, C. Pineda, L. Lemoine, P.M. Civello, G.A. Martinez, A.R. Chaves, Postharvest Biol Technol. 35, 69 (2005)
18. C. Ouhibi, H. Attia, F. Rebah, N. Msilini, M. Chebbi, J. Aarrouf, L. Urban, M. Lachaal, Plant Physiol Biochem. 83, 126 (2014)

19. M.E.V. De Araujo, E.G. Barbosa, R.S.L. de Araújo, I.R. Teixeira, F.A. Gomes, P.C. Corrêa, Ind Crop Prod. 137, 9 (2019)

20. L. Urban, F. Charles, M.R.A. de Miranda, J. Aarrouf, Plant Physiol Biochem. 105, 1 (2016)

21. C.D. Ferreira, G.H. Lang, I. da Silva Lindemann, N. da Silva Timm, J.F. Hoffmann, V. Ziegler, M. de Oliveira, Food Chem. 339, 127810 (2020)

22. L. Fan, X. Liu, X. Dong, S. Dong, Q. Xiang, Y. Bai, LWT. 139, 110553 (2021)

23. M. Melikoglu, C. Webb, Use of waste bread to produce fermentation products, in Food Industry Wastes. ed. by M. Kosseva, C. Webb (Elsevier London, 2013)

24. N. Ravimannan, P. Sevvel, S. Saarutharshan, Int J Adv Res Biol Sci. 3, 165 (2016)

25. C.M.B. Pinilla, R.C.S. Thys, A. Brandelli, Int J Food Microbiol. 293, 72 (2019)

26. S.O. Agunbiade, O.J. Ojezele, M. Barinemene, Chem Int. 6, 131 (2020)

27. C. Axel, E. Zannini, E.K. Arendt, Crit Rev Food Sci Nutr. 57, $3528(2017)$

28. O. Parenti, L. Guerrini, Trends Food Sci Technol. 99, 152 (2020)

29. I. Taglieri, C. Sanmartin, F. Venturi, M. Macaluso, A. Zinnai, S. Tavarini, A. Serra, G. Conte, G. Flamini, L.G. Angelini, Appl Sci. 10, 5235 (2020)

30. R. Klopsch, S. Baldermann, A. Voss, S. Rohn, M. Schreiner, S. Neugart, Fron Chem. 6, 322 (2018)

31. M.N. Unachukwu, C. Nwakanma, Int J Curr Microbiol Appl Sci. 4, 989 (2015)

32. M.V. Garcia, A.O. Bernardi, M.V. Copetti, Curr Opin Food Sci. 29, 1 (2019)

33. A.C. Ogodo, C.B. Nwaneri, D.I. Agwaranze, J.E. Inetianbor, C.U. Okoronkwo, Central Afr J Public Health 3, 44 (2017)

34. V. Fraberger, C. Ammer, K.J. Domig, Microorganisms. 8, 1895 (2020)

35. C. Hernandez-Aguilar, A. Dominguez-Pacheco, C. ValderramaBravo, A. Cruz-Orea, E.M. Ortiz, J. Ordonez-Miranda, Food Bioproc Tech. 13, 2104 (2020)

36. M.P. Thanushree, D. Sailendri, K.S. Yoha, J.A. Moses, C. Anandharamakrishnan, Trends Food Sci Technol. 93, 69 (2019)

37. M.E.B. da Rocha, F.D.C.O. Freire, F.E.F. Mai, M.I.F. Guedes, D. Rondina, Food Control 36, 59 (2014)

38. R. Torrijos, T.D.M. Nazareth, J.M. Quiles, J. Mañes, G. Meca, Foods. 10, 431 (2021)

39. A.A. El-Banna, P.M. Scott, J Food Prot. 46, 301 (1983)

40. R.A. Knight, E.M. Menlove, J Sci Food Agric. 12, 653 (1961)

41. M. Weidenbörner, C. Wieczorek, S. Appel, B. Kunz, Food Microbiol. 17, 103 (2000)

42. M. Nasir, M.S. Butt, F.M. Anjum, K.A. Sharif, R. Minhas, Int J Agric Biol. 5, 458 (2003)

43. M.E.J. Al-Defiery, A.F. Merjan, Mesop environ j. 1, 18 (2015)

44. H.A. Bosly, M.A. Kawanna, Toxicol. Ind. Health 30, 304 (2014)

45. N.H. Aziz, E.S. Attia, S.A. Farag, Food Nahrung 41, 34 (1997)

46. M. Ataila, N.M. Hassanein, A.A. El-Beih, Y.A. Youssef, Acta Pharm Sci. 46, 3 (2004)

47. R. Campagna, A. Romano, A. Raiola, P. Masi, G. Toraldo, S. Cavella, Food Bioprod Process. 119, 31 (2020)

48. A. Kumar, P. Rani, S.R. Purohit, P.S. Rao, J Cereal Sci. 96, 103094 (2020)

49. M.K. Demir, A. Elgün, J Food Sci Technol. 19, 195 (2013)

50. M.K. Demir, A. Elgün, J Food Sci Technol. 51, 59 (2014)

51. H.Q. Zhang, G.V. Barbosa-Cánovas, V.B. Balasubramaniam, C.P. Dunne, D.F. Farkas, J.T. Yuan (2011) (Eds) Nonthermal processing technologies for food Wiley-Blackwell UK 
52. V.V.S. Gopisetty, A. Patras, A. Kilonzo-Nthenge, S. Yannam, R.R. Bansode, M. Sasges, S.M. Burns, M.J. Vergne, C. Pan, H. Xiao, LWT. 95, 230 (2018)

53. A.K. Khan, R. Rashid, N. Fatima, S. Mahmood, S. Mir, S. Khan, N. Jabeen, G. Murtaza, Acta Pol Pharm. 72, 643 (2015)

54. F. Shahidi, P. Ambigaipalan, J Funct Foods. 18, 820 (2015)

55. B. Xu, S.K.C. Chang, J Agric Food Chem. 57, 4754 (2009)

56. G.A. González-Aguilar, M.A. Villegas-Ochoa, M.A. MartínezTéllez, A.A. Gardea, J.F. Ayala-Zavala, J Food Sci. 7, S197 (2007)

57. C. Liu, H. Zheng, K. Sheng, W. Liu, L. Zheng, Sci Hort. 241, 107 (2018)

58. J.C. Meneses-Reyes, R.M. Soto-Hernández, T. Espinosa-Solares, M.E. Ramírez-Guzmán, Agrociencia 42, 425 (2008)

59. M. Irakli, P. Chatzopoulou, L. Ekateriniadou, Ind Crops Prod. 124, $382(2018)$

60. A.R. Bilia, D. Salvini, G. Mazzi, Chromatographia 53, 210 (2001)

61. A.A.C.C., American Association of Cereal Chemists. (2000)

62. M. Laureati, B. Giussani, E. Pagliarini, Food Res Int. 46, 326 (2012)

63. C. Hernandez-Aguilar, A. Dominguez-Pacheco, M. Palma Tenango, C. Valderrama-Bravo, M. Soto Hernandez, A. CruzOrea, J. Ordonez-Miranda, J. Food Sci. Technol. 57, 1817 (2020)

64. P. Neergaard, The MacMillan Press LTD, London and Basinestoke. (1979)

65. M.C. Perez Reyes, C. Hernandez-Aguilar, A. DomínguezPacheco, A. Cruz-Orea, E. Moreno, E. Martínez, Int. J. Thermophys. 36, 2389 (2015)

66. C. Hernandez-Aguilar, A. Dominguez-Pacheco, C. ValderramaBravo, A. Cruz-Orea, E.M. Ortiz, R. Ivanov, J. Ordonez-Miranda, Curr Res Nutr Food Sci. 4, 521 (2021)

67. N. Ravimannan, P. Sevvel, S. Saarutharshan, Int. J. Adv. Res. Biol. Sci. 3, 165 (2016)

68. SAS., Release 8.01. SAS Institute Inc., Cary, N. C. USA (2008)

69. R.D.G. Steel, J.M. Torrie, 2-edition (Mc Graw Hill, New York, 1980)

70. M. Kawaguchi, A. Kani, K. Takatori, Biocontrol Sci. 24, 179 (2019)

71. C.U. Pala, A.K. Toklucu, J Food Compos Anal. 24, 790 (2011)

72. F.D.A. Ultraviolet radiation for the processing and treatment of food. Code of Federal Regulations, 21 CFR 179.39, United States Food and Drug Administration (2013)

73. E. Cantos, C. García-Viguera, S. de Pascual-Teresa, F.A. TomásBarberán, J Agric Food Chem. 48, 4606 (2000)

74. M.D. Gurol, R. Vatistas, Water Res. 21, 895 (1987)

75. P. Gélinas, C.M. McKinnon, Int J Food Sci Technol. 41, 329 (2006)
76. K.K. Adom, M.E. Sorrells, R.H. Liu, J Agr Food Chem. 51, 7825 (2003)

77. H.G.C. King, J Food Sci. 27, 446 (1962)

78. R. Meral, Y.E. Köse, Qual Assur Saf Crop Foods. 11, 171 (2019)

79. U.K. Ibrahim, R.M. Salleh, S.N.S. Maqsood-ul-Haque, Int J Food Eng. 1, 39 (2015)

80. E.S.M. Abdel-Aal, P. Hucl, F.W. Sosulski, R. Graf, C. Gillott, L. Pietrzak, J Agr Food Chem. 49, 3559 (2001)

81. M. Srinivasan, A.R. Sudheer, V.P. Menon, J Clin Biochem Nutr. 40, 92 (2007)

82. L. Cisneros-Zevallos, J Food Sci. 68, 1560 (2003)

83. J.L. Mau, P.R. Chen, J.H. Yang, J Agr Food Chem. 46, 5269 (1998)

84. EFSA Panel on Dietetic Products Nutrition and Allergies (NDA), Scientific Opinion on the safety of vitamin D-enriched UV-treated baker's yeast. EFSA J. 12(1), 3520 (2014)

85. Q. Xiang, L. Fan, R. Zhang, Y. Ma, S. Liu, Y. Bai, Food Control 111, $107082(2020)$

86. L. Niu, Z. Wu, L. Yang, Y. Wang, Q. Xiang, Y. Bai, J Food Prot. 84, 139 (2021)

87. N.L.M. Castro, Cumbres. 2, 49 (2016)

88. A. Demirci, K. Krishnamurthy, Pulsed ultraviolet light. In:Zhang, H.Q., Barbosa-Cánovas, G.V., Balasubramaniam, V.M.,Dunne, C.P., Farkas, D.F., Yuan, J.T.C. (Eds.), Wiley-Blackwell, 249 (2011)

89. O. Vidal-Casanella, N. Nuñez, S. Sentellas, O. Núñez, J. Saurina, Separations 7, 23 (2020)

90. K. Kljak, D. Grbeša, D., Karolyi, J. Cereal Sci. 2, 109 (2014)

91. A.J. Meléndez-Martínez, I.M. Vicario, F.J. Heredia, J Agric Food Chem. 55, 2808 (2007)

92. A.S. López-Díaz, E. Palou, A. López-Malo, Temas selectos de Ingeniería de Alimentos. 6, 79 (2012)

93. B. Phongnarisorn, C. Orfila, M. Holmes, L.J. Marshall, Foods 7 , 17 (2018)

94. K. Abbasi, A.A. Shah, Int J Curr Microbiol Appl Sci. 4, 236 (2015)

95. V.M. Patil, S. Das, K. Balasubramanian, J Phys Chem A. 120, $3643(2016)$

Publisher's Note Springer Nature remains neutral with regard to jurisdictional claims in published maps and institutional affiliations. 